Article

\title{
Unintended Side Effects of the Digital Transition: European Scientists' Messages from a Proposition-Based Expert Round Table
}

\author{
Roland W. Scholz 1,2,*(D), Eric J. Bartelsman ${ }^{3}$, Sarah Diefenbach 4 (D), Lude Franke ${ }^{5}$, \\ Arnim Grunwald ${ }^{6,7}$ (D), Dirk Helbing ${ }^{8}$, Richard Hill ${ }^{9}$, Lorenz Hilty ${ }^{10,11}$ (D), Mattias Höjer ${ }^{12}$ (D), \\ Stefan Klauser ${ }^{8}$, Christian Montag ${ }^{13,14}$ (D), Peter Parycek ${ }^{15,16}$, Jan Philipp Prote ${ }^{17}$, \\ Ortwin Renn ${ }^{18}$, André Reichel ${ }^{19}$, Günther Schuh ${ }^{17}$, Gerald Steiner ${ }^{1}$ \\ and Gabriela Viale Pereira ${ }^{16}$
}

1 Department Knowledge and Information Management, Danube University of Krems, 3500 Krems an der Donau, Austria; Gerald.Steiner@donau-uni.ac.at

2 Department of Environmental Systems Sciences, ETH Zurich, 8092 Zurich, Switzerland

3 Department of Economics and Tinbergen Institute, Vrije Universiteit Amsterdam, 1081 HVAmsterdam, The Netherlands; e.j.bartelsman@vu.nl

4 Department of Psychology, LMU Munich, 80539 Munich, Germany; sarah.diefenbach@psy.lmu.de

5 Department of Genetics, University of Groningen, University Medical Centre Groningen, 9700 CC Groningen, The Netherlands; 1.h.franke@umcg.nl

6 Institute for Technology Assessment and Systems Analysis (ITAS), Karlsruhe Institute of Technology (KIT), 76131 Karlsruhe, Germany; armin.grunwald@kit.edu

7 Office of Technology Assessment at the German Bundestag (TAB), 10178 Berlin, Germany

8 Department of Humanities Social and Political Sciences ETH Zurich, 9092 Zurich, Switzerland; dirk.helbing@gess.ethz.ch (D.H.); stefan.klauser@gess.ethz.ch (S.K.)

9 Hill \& Associates, 1207 Geneva, Switzerland; rhill@hill-a.ch

10 Department of Informatics, University of Zurich, 8050 Zurich, Switzerland; hilty@ifi.uzh.ch

11 Swiss Federal Laboratories for Materials Science and Technology (EMPA), 9014 St. Gallen, Switzerland

12 Division of Strategic Sustainable Studies, Department of Sustainable development, Environmental Science and Engineering, KTH Royal Institute of Technology, SE-10044 Stockholm, Sweden; hojer@kth.se

13 Department of Molecular Psychology, Institute of Psychology and Education, Ulm University, 89069 Ulm, Germany; christian.montag@uni-ulm.de

14 SCAN Laboratory, Clinical Hospital of the Chengdu Brain Science Institute and Key Laboratory for Neuroinformation, University of Electronic Science and Technology of China, Chengdu 611731, China

15 Center of Competence Public IT at Fraunhofer FOKUS, 10589 Berlin, Germany; peter.parycek@donau-uni.ac.at

16 Department for E-Governance and Administration, Danube University Krems, 3500 Krems an der Donau, Austria; gabriela.viale-pereira@donau-uni.ac.at

17 Production Management Department, Laboratory for Machine Tools and Production Engineering (WZL), RWTH Aachen, 52056 Aachen, Germany; j.prote@wzl.rwth-aachen.de (J.P.P.);

G.Schuh@wzl.rwth-aachen.de (G.S.)

18 Institute for Advanced Sustainability Studies (IASS), 14467 Potsdam, Germany; ortwin.renn@iass-potsdam.de

19 International School of Management (ISM), 70180 Stuttgart, Germany; andre.reichel@ism.de

* Correspondence: roland.scholzr@emeritus.ethz.ch; Tel.: +41-79-4224401

Received: 9 May 2018; Accepted: 7 June 2018; Published: 13 June 2018

Abstract: We present the main messages of a European Expert Round Table (ERT) on the unintended side effects (unseens) of the digital transition. Seventeen experts provided 42 propositions from ten different perspectives as input for the ERT. A full-day ERT deliberated communalities and relationships among these unseens and provided suggestions on (i) what the major unseens are; (ii) how rebound effects of digital transitioning may become the subject of overarching research; 
and (iii) what unseens should become subjects of transdisciplinary theory and practice processes for developing socially robust orientations. With respect to the latter, the experts suggested that the "ownership, economic value, use and access of data" and, related to this, algorithmic decision-making call for transdisciplinary processes that may provide guidelines for key stakeholder groups on how the responsible use of digital data can be developed. A cluster-based content analysis of the propositions, the discussion and inputs of the ERT, and a theoretical analysis of major changes to levels of human systems and the human-environment relationship resulted in the following greater picture: The digital transition calls for redefining economy, labor, democracy, and humanity. Artificial Intelligence (AI)-based machines may take over major domains of human labor, reorganize supply chains, induce platform economics, and reshape the participation of economic actors in the value chain. (Digital) Knowledge and data supplement capital, labor, and natural resources as major economic variables. Digital data and technologies lead to a post-fuel industry (post-) capitalism. Traditional democratic processes can be (intentionally or unintentionally) altered by digital technologies. The unseens in this field call for special attention, research and management. Related to the conditions of ontogenetic and phylogenetic development (humanity), the ubiquitous, global, increasingly AI-shaped interlinkage of almost every human personal, social, and economic activity and the exposure to indirect, digital, artificial, fragmented, electronically mediated data affect behavioral, cognitive, psycho-neuro-endocrinological processes on the level of the individual and thus social relations (of groups and families) and culture, and thereby, the essential quality and character of the human being (i.e., humanity). The findings suggest a need for a new field of research, i.e., focusing on sustainable digital societies and environments, in which the identification, analysis, and management of vulnerabilities and unseens emerging in the sociotechnical digital transition play an important role.

Keywords: digital transformation; digital curtain; digital vaulting; unintended side effects (unseens), proposition-based expert round tables

\section{Scope and Goals}

\subsection{Digitalization as a Main Driver of Human Socio-Cultural Evolution}

The digital revolution comprises one of the major transitions of human development. We may consider it to be as critical as the mastery of fire, the development of language, or the first Industrial Revolution [1]. Whereas the latter was characterized by the extension of human activity and economics by supplementing organic (photosynthesis-based) energy in plants with the use of energy from fossil fuel (i.e., starting with coal), the main technological essence of the Digital Revolution is the exponential increase in the speed and amounts of storage, processing, retrieval, and communication of digital data. Thus, the empowerment, extension, and substitution of human physical power are followed by an empowerment of cognitive or mental power. Digitalization (used synonymously with digitization) is the representation of discrete or analog (real-world) objects or processes in the form of digital symbols. The major roots of digitalization are found in the history of the invention of place-value numbers and the number zero, about 2600 years ago [2-4]; binary numbers 500 years ago; the first programmable computer invented by Babbage (1791-1871) [5], followed by Boole's (1815-1864) symbolic logic; and-as a key entrance to technological implementation-Zuse's programmable, digital computer in 1941. We may consider the year 2002 as the start of the Digital Age, if we refer to the criterion provided by Hilbert [6] that the majority of human-produced information has, by now, been stored digitally. Given the World Wide Web, distributed and pervasive computing inventions such as Nelson's hypertext leading to the internet played an important role [7]. 
Digital technologies are machines that master digital representation, computing, and adapting (learning) related to environmental information. We do not deal with the history of technology in detail. Yet we want to mention that the history of Moore's law, with a doubling of the density of transistors (defined as the numbers of transistors per circuit) and thus the doubling of storage capacities, has not yet come to an end [8,9], although there are strong arguments that the present technology will reach its physical boundaries [10]. However, there are new computing technologies such as quantum computers that will open new doors to algorithmic complexity, encryption, and machine learning [11,12] and cell-based biocomputers that may lead to the perspective of hybrid biotechnological systems $[4,13]$.

Digital technologies are operating on and changing all levels of human systems. There are programmed, cancer-fighting nanorobots that destroy (marked) tumor cells [14]. Brainwaves may be read by computers to steer cars. Individuals immerse themselves in virtual gaming worlds. Human bonds are forged and maintained $24 / 7$, as people scattered all across the globe Skype keep relations with friends and family. Virtual companies play important roles in pharmaceutical developments [15]. Countries such as Estonia utilize digital technology for managing all public services. The global internet and its social networking platforms has become a primary communication system among humans and is building something like the mind of the human species. Digital technologies are all-purpose technologies and transform processes and life in all domains of the planet.

\subsection{The Rush for a Better Society by Digitalization}

All of the European countries have high expectations with respect to digital transitioning. However, Europe's 2017 Digital Progress Report for EU countries [16] documents a high level of variance in the integration of digital technologies, with Scandinavian countries and several smaller countries at the top and Romania and Bulgaria scoring lowest. This assessment is based on a Digital Economy and Society Index including connectivity, digital skills, internet use and the use of digital technology in business and public services. Almost every country has developed something like a national Digital Agenda [17] or Digital Strategy [18]. The aims are to boost economic progress, the supply of health care, connected and autonomous mobility, efficient energy and resource use, wealth and (international) competitiveness, and so on, as well as a comprehensive digital public service with a focus on strengthening democracy.

Yet, presumably, any large-scale technology transition is linked to beneficial—but also unfavorable and unwanted - changes for almost all actors included or concerned. The three decades of discussion about the productivity paradox, starting with Solow's 1987 statement [19] that we cannot see productivity increase caused by computers, have been modified by Brynjolfsson and colleagues' sophisticated business-systems transition analysis [20-22] and have culminated in recent meta-analyses [23,24] that reveal that digital technology is the trigger and catalyst for a fundamental societal transition and economic growth. This transition is linked to synchronous and delayed positive and negative changes on sociocultural and material-biophysical levels. We may argue that this is a key matter for sustainability science, in particular if we consider the anticipation of critical unintended side effects (unseens) of technology innovation on various domains of society as the art of sustainability learning [25]. In this context, the anticipation of unseens may be considered a critical factor in sustainability learning. Therefore, we approach sustainability from a systemic perspective when conceiving sustainable development as an (i) ongoing transdisciplinary inquiry on (ii) managing systemic limits (i.e., for avoiding hard landings) in the frame of (iii) inter- and intragenerational (global) justice [26,27].

\subsection{Identifying Unintended Side Effects of Digital Transitioning as Objectives of Proposition-Based Expert Round Tables (ERTs) on Sustainable Digital Environments}

Please note that unseens are not the barriers that harm development. In decision-theoretic terms, an unseen is a positive or negative impact that results from an action $A$ on a system $B$ that was not intended by the decision maker (or by those who were involved in the planning or realization of an action). Thus, in general, we distinguish between intended impacts and unintended impacts of an action. 
Unintended impacts are usually unanticipated. Harvesting crops in (early) agriculture may serve as an example. The goal and intention of ancient farmers was to grow as much of a crop as possible on arable land. The unseen was the consequential reduction of nutrients and, thereby, of the harvest. This unseen was compensated (mitigated) by the invention of fertilizing or other means (such slash and burn agriculture which may be conceived as adaptation). We want to note that unseens may affect the same system as that of the intended impacts or a different system (which may not be in the primary interest of the decision maker).

Unanticipated barriers in the course of implementing a technology are not conceived as unseen. If, for instance, unexpected high costs or public concerns prevent the implementation of a technology (such as GMOs as food in some European countries), these negative aspects are conceived as potentially unknown (or unanticipated) costs for implementing a technology (i.e., making a decision $A$ ).

Additionally, the goal of these Expert Round Table (ERT) was (launched by the first author) to increase awareness among the science community that the digital transitioning (including the digital divide) is a core issues of sustainable science. Based on this, the identification of unseens was conceived as a step for preparing science for transdisciplinary processes. A transdisciplinary process [28-30], is a knowledge-integration-based, real-world, problem-oriented discourse including representatives from all key stakeholder groups that is intended to generate socially robust orientations on critical issues of sustainable development $[28,29]$. For instance, the facilitation of the adaptation and/or the mitigation process for those who cannot benefit from the desired advantages of digital transitioning may become the subject of a transdisciplinary process related to the Digital Revolution.

The goals of the European ERT, as well as those of a previous Japanese ERT [31] that took place in February 2017 [32], read as follows:

- Goal 1: Identify positive or negative unsee(ns) that are linked to digital transitioning;

- Goal 2: Reflect on the way(s) in which the unsee(ns) can best become subjects of science in an overarching way;

- Goal 3: Project (from the science perspective) which unsee(ns) might become subjects of transdisciplinary processes (i.e., science-practice discourses that relate different types of knowledge in order to efficaciously master complex, relevant societal challenges).

The present paper presents and classifies the unseens and compares them with those from a Japanese ERT which took place in February 2017 and develops a bigger picture on sensitive domains which are not yet well understood and which ask for further research policy means. The propositions of Appendix A address the above goals and a basic pillar of this paper. Before we present the method of proposition-based (Science) ERT, and findings of the European ERT, we briefly summarize the main findings of the Japanese ERT.

\subsection{Main Findings, Unseens, and Conclusions of the Japanese 2017 ERT}

The Japanese ERT followed the same Goals 1-3 as presented above. The outcomes were published by Sugiyama et al. [31] and are summarized to some extent in Appendix B. The main digital-technology innovations identified were automatization, Big Data, artificial intelligence (AI), conversational software, and digital biotechnology (including biocomputers). Globalized networking and ubiquitous availability in all domains of life were identified as unique selling points of digital technologies.

Three issues that are less frequently discussed may be of special interest. The first is that culture (and religion) matters in the use and acknowledgement of digital technology. The experts argued that the Japanese (given a Shinto and Buddhism cosmology) prefer embodied, humanoid robots, whereas Christian principles of resurrection and salvation allow for the appreciation of nonhumanoid robots. The second refers to concerns related to endogenous black-swan-like threats that endanger financial, military, and other large-scale digital systems. Third, several propositions provided by Scholz and Sugiyama refer to biotech. Scholz [4], who also provided propositions to the Japanese ERT, conceives deoxyribonucleic acid (DNA) and GMO as genetically modified organisms (GMO) 
(quaternary number-based) entities and operations. In this context, critical impacts from directed evolution become unseens from digital technology. But, in addition, reduced conceptions of evolution due to the preponderance of the digital theory of molecular genetics (this is elaborated in Appendix B) were identified as inner-science unseens. In the context of biotechnology, special attention was also given to biocomputers, which include living cells which are conceived as cognitive systems [33] and decision-makers [34] rather than as mere electrochemical processes. Concerns were raised about the kind of governance that would be necessary for these types of bionic entities.

\section{Theory: Approaching a Classification of Unintended Side Effects (Unseens)}

\subsection{Defining Human Systems, Environmental Systems, and the Digital Environment}

The digital transition is a genuine human-made issue. For investigating and analyzing unseens, we take a decision-making perspective. As a point of departure, a (digital) technology is considered as a means (i.e., decision alternative, $A_{D}$, also denoted as a digital, $D$, technology innovation) that is invented, established, or used by a decision maker (i.e., a human individual, a company, or a government, denoted by $H$ ) to acquire some positive outcome (i.e., some positive utility payoff) from an intended change in the environment, $E$. Unseens are nonperceived or unanticipated (negative) side effects. From a system-theoretic perspective, the management of digital technologies calls for a symbiotic coevolutive connection with all human systems, in particular the social, economic, and political processes [35].

The digital environment $E_{D}$ comprises all human-made processes that rely on digitally represented information. The (discrete) digital nature and computational (processing-based) nature are essential. Following the Human-Environment System (HES) framework [25], the cell (including its self-creating programs and its capability to decide) is considered the basic unit of life. The definition of the human individual and of its environment follows this definition. According to HES, the human environment, $E$, complements (the atoms of) all living cells of an individual that emerged from the zygote and their interactions. The HES framework distinguishes between the material-biophysical layer, $H_{m}$ (the "body"), which is inextricably coupled with a social-epistemic-cultural layer $H_{s}$ (the "mind"), and there is a hierarchy of human systems above and below the human individual. The (main) levels above the individual are the (human) group, organization (commercial and non-commercial), institutions (organizations which are established by societies), societies (the major subdivision of human species [36]), and the human species. According to the cell-based definition, a company (as one type of organization) consists of the activities of the living cells of all owners and employees assigned to this company. Similarly, other human systems may be defined. Below the human system, we distinguish the organ, tissues, cell systems, and the single cell. The forthcoming analysis of expert's views on unseens and the discussion of the results refers to the presented complementarities and the hierarchy postulate of the HES framework as presented in this section (see [25,37]).

The environment, E, of a human system consists of - simplified-all the atoms of the universe minus the atoms of the cells which make the human system, $H$. We distinguish between a (living) biotic (cell-based) and an abiotic environment (see Figure 1). As there are biocomputers that include living cells $[4,13]$, the digital environment may also be distinguished by a (traditional) abiotic digital environment, $E_{m-a b i o-d i g i}$, and a biotic one that includes both a material one, $E_{m-b i o-d i g i}$ and (if we consider the cell as a cognitive system [33,38]) a social-epistemic-cognitive level, $E_{m-b i o-d i g i,}$ as well, In this context, it is essential that digital technologies allowed to monitor (and even to visualize) nanostructures, e.g., the genetic code. This opens the floor to new horizons. Against this background —as technology may be conceived as "idea, volition, or knowledge" [39]—-the genetic modification of organisms (GMO) has been seen as part of the digital environment and denoted as one of the major threats to human development $[4,40]$.

The paper focuses on unseens related to societally relevant impacts. However, the science system itself will also be subjected to fundamental changes through digitalization (see also Section 1.4 and Appendix B.1). Bruno Latour's work on the sociology of science revealed that computerization 
changed life in the biological research laboratory in a most fundamental manner [41]. He stated that the change in scientific work (tending to become more fragmented) is even greater than the shift from experimentation to simulation. There are also fundamental changes in modeling caused by digitalization. Some scientist stress that the shift from analytic mathematical theory-based modeling to computational, discrete mathematics is linked to different types of validation errors (e.g., round-off or truncation errors). This has affected, for instance, climate research (where continuous functions of time and space are transferred to discrete points) [42]. From a philosophy of science perspective, it is of interest that different notions of meaning that are assigned to mathematical theorems (which partly represent natural laws in a nomothetical manner) and to algorithms (which are mostly conceived as descriptive tools) [42,43]. Moreover, mathematics itself has been fundamentally affected by the invention of the computer; there is a shift to computer-based or automated theorem proving in mathematics [44,45], as indicated by the question, "How can we believe in a machine-checked proof?" [46]. Referring to Figure 1, this establishes a new relationship between the individual mathematician's mind and (a formerly) written (chalk-and-blackboard, technology-based) mathematical theorem whose verification is now mediated by a machine-based computational layer (as a specific form of the digital curtain) and does not only rely on the mathematical expert.

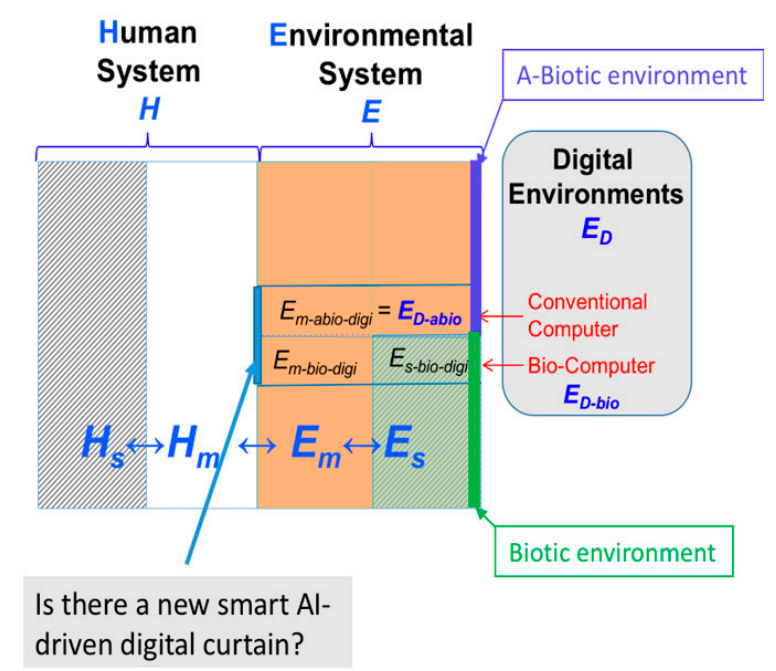

Figure 1. Digital systems at the interface between human systems (that have a social-epistemic-cultural layer that includes digital knowledge and a material biophysical level) that interacts with the biotic and abiotic environment. The digital environment is increasingly an intermediate layer between the human system and the environment. This is called digital vaulting.

\subsection{Innovations in the World of Digital Technologies}

The smart and connected world in which services, products, and people are somehow embedded in broader systems, is reshaping society. Emergent domains such as Web 3.0, Industry 4.0, Government 3.0 (Refer to Gov3.0 project: http:/ / www.gov30.eu/), or even Life 3.0, which discusses the implications of artificial intelligence on the future of life on Earth, are changing the role of digital technologies and the data on designing and rethinking human systems. For example, in the industry sector, the pervasiveness of digitization has been reshaping products toward a layered architecture that includes devices, networks, services, and contents [47].

Digital products share three main elements: physical components, smart components (sensors, microprocessors, data storage etc.), and connectivity components (especially the networks that provide communication within the system, see [48]). The same is happening in the public sector, where new possibilities for innovating governance have been created by the growth in data, computational power, and social media [49], as well as by the digital city governance concept where cities require smart 
and connected public services (and their related design and development), smart decision-making processes, integrated public policies, and new governance structures.

From a data-driven perspective, we can distinguish between the storage, retrieval, processing (the algorithmic part), and transmission (the network part) of digital data. Storage, often resulting in Big Data, can use decentralized, centralized, and partially networked storage units including cloud storage. The encryption and access to its code is a key to data security. Multiauthority cloud-storage systems are seen as overcoming the mono-emperorship that has been linked to a central data-control authority.

Another critical issue of storage at the interface to retrieval is the longevity of data. The history of Information and Communication Technologies (ICT) is full of variants of unfulfilled expectations with respect to overcoming the aging effects of storage media such as magnetic tapes, optical CDs, and semiconductor transistors, and other developed technologies all have critically low lifetimes. Robust, potentially long-term storage systems that demonstrate the same level of performance as papyrus scripts that are hundreds of years old are not yet in sight. How Big Data may be reliably retained is, as yet, unanswered.

With respect to retrieval, the potential for hacking and the vulnerability of economic, medical, and infrastructure data is also an unsolved problem. Table 1 describes important factors related to the main operations related to digital data and technology innovation that may cause unseens.

Table 1. Main operations and technologies related to digital data and technology innovation that may cause unseens.

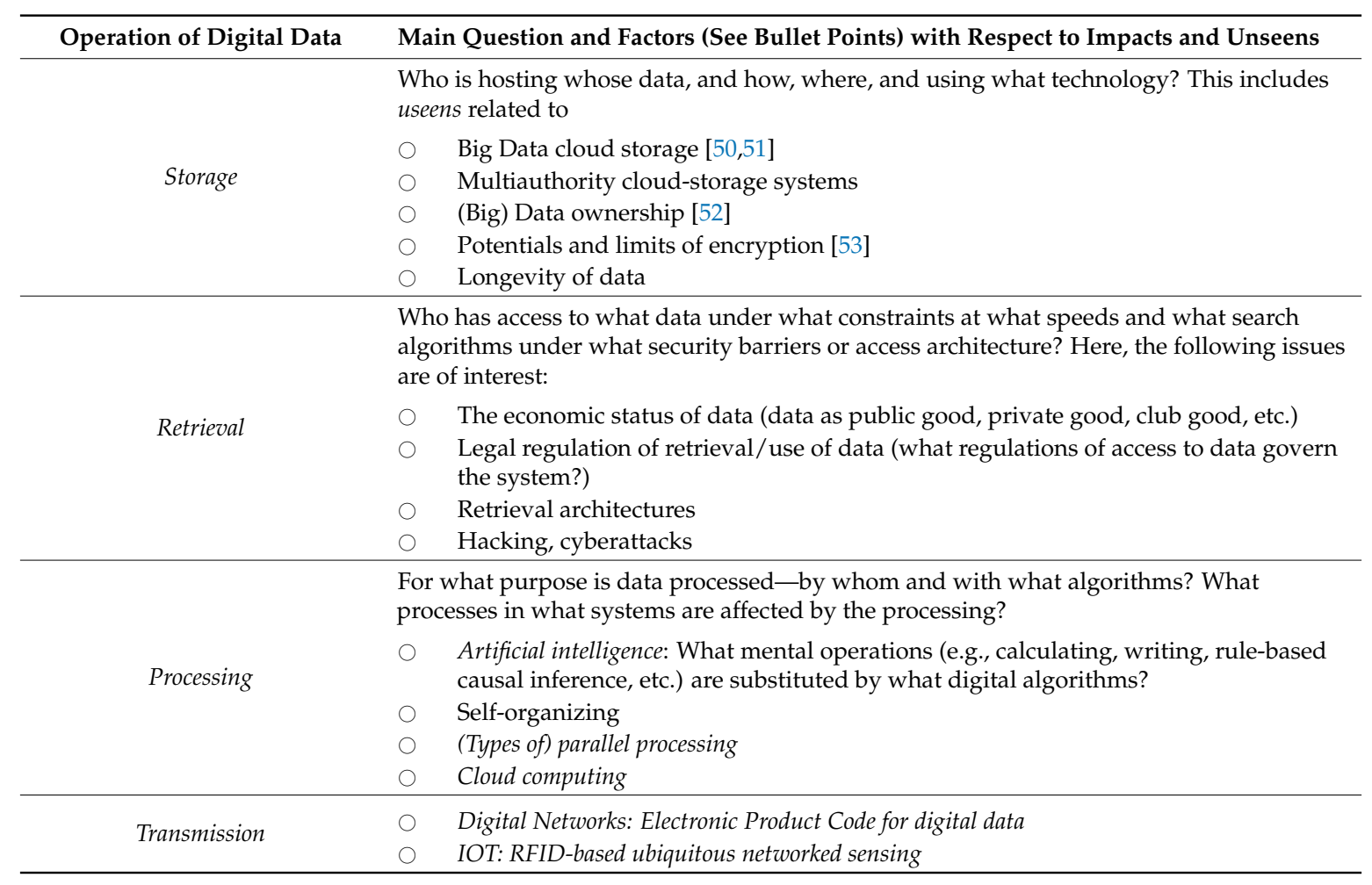

\subsection{New Types of Digitalized Environments}

Digital technology and the above-mentioned sub-components are general-purpose technologies. This is best expressed by terms such as pervasive computing [54], distributed systems, networks, systems of systems, or the Internet of (Every-)Thing (IoT). A key issue of technology transitioning is that the new technology induces a fundamental restructuring of social, production, business, and other processes. It was not the steam engine itself but the adjustment of production by transmission belts, energy, insertion in vehicles, etc. that led to trains, new types of workers, and technological knowledge that transformed human life and Earth. These developments, in turn, led to new environments 
such as industrial cities, new forms of education at institutes of technology, new forms of poverty, and capital as a key variable of economic systems. We can find the same kinds of developments in the digital transition.

\section{Procedure/Methods/Data Sampling}

\subsection{Invitation, Procedure, Sampling of Data, Methods of Data Anylysis}

After the Japanese ERT in Tokyo (19 February 2017), the organizers of the European ERT (Scholz, Parycek, and Steiner) defined a tentative list of perspectives and potential contributors who should participate in the ERT. The initial plan was to include representatives from economics and industry, and experts in biogenetics, cyberwarfare, and integrated world systems. Based on a phone chain, the scientists presented in Table 2 made commitments to participate in the ERT.

Finally, 17 European science experts working in 8 different European countries provided 42 propositions (see Appendix A) on the 10 perspectives. The scientists were asked to focus on unseens. Some proposals had to be rewritten several times, as the experts were focusing only on the phenomena related to digital transitioning. Based on this, a "Workbook for Preparing the European Round Table Structuring Research on Sustainable Digital Environments" was created (see Supplementary Materials 1). This 43-page workbook included all propositions and a glossary with referenced definitions including the following key terms: digital revolution, transition, and transformation; sustainability/sustainable development; transdisciplinarity; and unseens. All participants received the workbook a week before the ERT was to convene.

Table 2. Perspectives and (scientific) experts who wrote propositions for unseens. Perspectives 6 and 7 $\left(\right.$ marked with ${ }^{*}$ ) were not represented at the ERT ${ }^{1}$ (participating experts are marked with ${ }^{+}$, the country of primary institutional association is shown in parentheses).

\begin{tabular}{cll}
\hline No. & \multicolumn{1}{c}{ Perspective } & \multicolumn{1}{c}{ Experts (Country) } \\
\hline 1 & Industrial change & G. Schuh ${ }^{+}(\mathrm{D})$ \& J. Prote (D) \\
2 & Economic change & E. Bartelsman (NL) \\
3 & Environmental systems & M. Höjer (S) \& L. Hilty (CH) \\
4 & Social \& neuropsychology & S. Diefenbach (D) \& C. Montag ${ }^{+}(\mathrm{D})$ \\
5 & Genetics & L. Franke (NL) \\
6 & Big Data analytics & P. Parycek (A) \& G. Viale Pereira (A) \\
$7^{*}$ & Cybersecurity \& warfare & R. Hill ${ }^{+}(\mathrm{CH} / \mathrm{GB})$ \\
$8^{*}$ & Ethics \& the Digital & C. Kirchner ${ }^{+}(\mathrm{F})$ \& G. Dowes ${ }^{+}(\mathrm{F})$ \\
9 & Global social change & D. Helbing ${ }^{+}(\mathrm{CH})$ \& S. Klauser (CH) \\
10 & Sustainable development & A. Grunwald (D) \& O. Renn (D) \\
\hline
\end{tabular}

\footnotetext{
${ }^{1}$ The ERT was moderated by R. W. Scholz (A) and P. Parycek (A); K. Fritsche (D) and A. Reichel (D) participated as discussants.
}

The one-day ERT took place in Bonn on 19 September 2017. Eleven of the authors of the propositions, the first author as moderator, two invited discussants (see Table 2, and five representatives of the German Ministry of Education and Research (BMBF) joined the ERT. After a brief presentation of the background and general message, each set of proposals (accessible to participants in the workbook) was discussed for 30-40 min to develop a deeper understanding on a specific perspective message. The experts had been informed of the highlights of the Japanese ERT by mail before the ERT in Bonn and via the pinboard. The main steps of this proposition-based ERT is presented in Figure 2. 


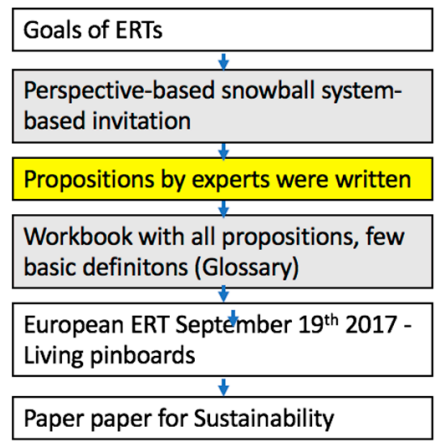

Figure 2. Steps of the European Expert Round-Table (ERT) on structuring research for sustainable digital environments.

In the course of the ERT, the participating science experts were asked to provide suggestions/inputs by key words (key topics) to four (living) pinboards (see Supplementary Materials II). 1: Priority list of unseens: Most urgent rebounds/unseens/digital threats calling for special treatment (see Goal 1 of the ERT above); 2: Blind spots and overarching layers: What has not yet been sufficiently discussed in the propositions of the Tokyo and the European ERTs? 3: Overarching conceptual layers: This topic referred explicitly to Goal 2, i.e., on the question of how unseens may become the best subjects of research. 4: Candidates for Td Processes: What key stakeholders of what domain of digital transitioning are interested in a transdisciplinary process?

\subsection{Data Analysis}

\subsubsection{Main Messages}

Right after the workshop, (i) main conclusions were elaborated in the final discussion. These conclusions and others developed throughout the entire workshop were summarized by two authors (Reichel and Scholz) and sent to all participants of the ERT (see Box 1) for any corrections and supplementations.

\subsubsection{Classifying Unseens}

For (ii) classifying unseens, the essence was extracted from the proposals. Appendix C presents short labels for identified unseens, the main technology innovation related to each one, the primary intended change of this technology innovation, and a brief description of the properties of each unseen. This table was constructed by two participants of the ERT (Scholz and Viale Pereira) with a face validity check by two other scientists (Clemens Fischer and Reiner Czichos). Several propositions were skipped (such as transdisciplinarity; see A.10.4), as they did not deal with an unseen. Some propositions were merged since they dealt with the same issue. Thus, from the 42 propositions, 30 different unseens were extracted.

For classifying the extracted unseens $\left(A_{i, k}=A i, k\right)$, a bottom-up strategy was chosen. Based on the description of the identified unseens in the propositions (see Appendix A), 34 salient issues (main issues; $I_{n}$ ) were identified by two authors (Scholz and Viale Pereira). A salient issue is defined here as the main aspect that characterizes a proposition.

Three authors (Scholz, Steiner, Viale Pereira) provided ratings on the question, to what degree are the (potentially negative) impacts addressed by or related to the item (e.g., $I_{1}$ : Loss of democracy) in the proposition (e.g., A.5.1, DNA-based discrimination) in individual sessions? The ratings were presented on a three-level scale ranging from "not at all" (=0) to "some significant extent" (=1) to "very much" (=2). The raters received instructions on how to cope with ambiguities. Supplementary Information 3 provides some insight into the ambiguities of the ratings. 
In order to mitigate subjective-rater bias, the 1088 ratings on $34 \times 32$ pairs of items and propositions by the three authors were adjusted in the following manner: The squared difference secures ensures that the main features are affecting the grouping/clustering of the data. For stressing contrasts, Ward's method was chosen $[55,56]$. To avoid being biased by the set of propositions, the raters were instructed never to rate two relationships between propositions and ratings in a row. The mean of the ratings of the three raters was taken as input for the Life Cycle Assesment (LCA).

\section{Results}

\subsection{Unseens Discussed in the European ERT}

For structuring the 31 unseens from the 42 propositions of the European ERT (see Appendix C), a hierarchical CLA [56] was applied based on mean judgments of three raters.

Figure 3 presents six main clusters (the interested reader should look at the propositions in Appendix A). First, clusters $\mathrm{C} 1$ and $\mathrm{C} 2$ (belonging to one supercluster) include the propositions on the dark side of digital transitioning on the societal level, C1 Cybernetics and warfare, and on the level of the individual (see the propositions of Hill and Kirchner/Dowes), C2 Psychoneurological sensitivity (Montag and Diefenbach).

A7.3 Digital war convention
A7.5 Warbots
A8.5 Roethics
A7.2 Cyberwar
A2.4 Property rights
A8.1 DNA-based discrimination
A8.1 Computation ethics
A8.5 Cybersecurity ethics
A4.3 Psychoneurol. effects
A4.4 Emotional needs
A4.1 Human robot
A4.2 Fragemented life
A4.2 Democracy
A10.2 Manipulated democracy
A6.4 Digital policy making
A6.4 Cybersocial systems
A6.3 Resilience governance
A3.1 Rebounds in environment
A3.3 Rural home offices
A3.4 Smart buildings
A10.1 Efficiency rebounds
A2.2 Digitalized labor
A1.2 Redefining labor
A2.1 Knowledge economy
A2.3 Inequality
A1.3 Customer-driven production
A1.4 Platform economics
A1.1 Industrie 4.0
A9.3 Democratic capitalism
A10.3 Unintegrated systems
A9.3 Finance 4.0

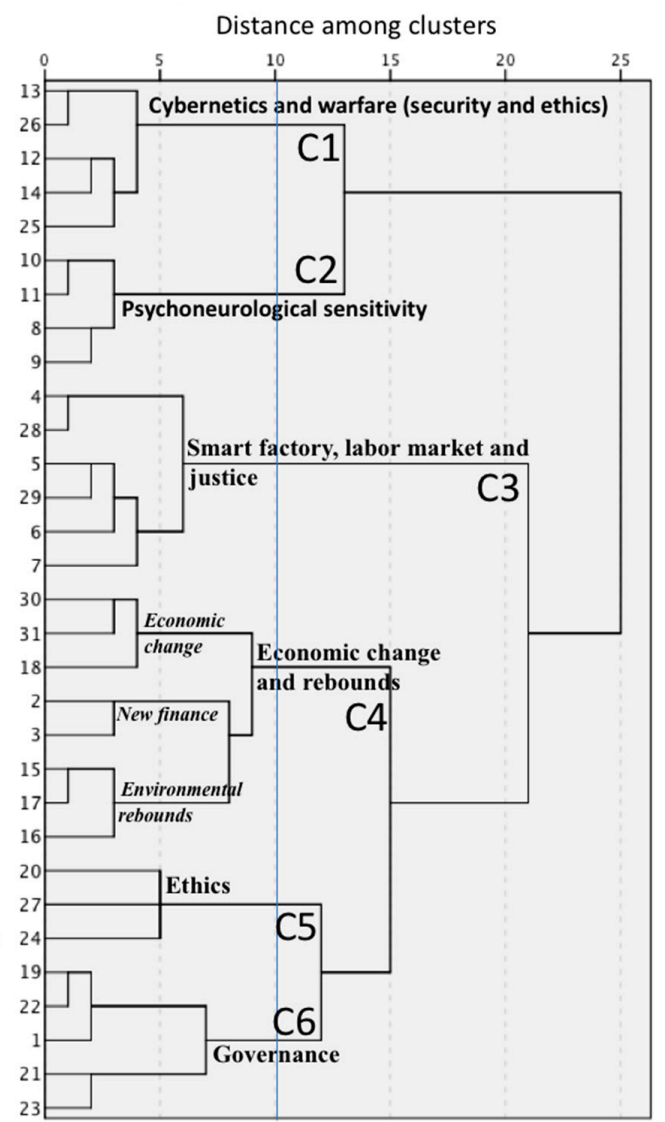

Figure 3. The main clusters among 31 unseens of the European ERT (the numbering, $A_{i, k}$ refers to the perspectives $i=1, \ldots, 10$ taken-see Table 2, and the number proposition of that perspective; see Appendix A).

The second supercluster includes four subclusters, C2-C4. The Smart factory, labor market, and justice cluster (C2) has roots in the Industrial change (Schuh and Prote) and Economic change (Bartelsman) perspectives (see Appendix A). 
Cluster C4, Economic change and rebounds, includes digital innovation of business and finance (addressed by Schuh and Prote), New finance (i.e., financial systems, emerging from Global Societal Change; Helbing \& Klauser), and Environmental rebounds (per Höjer and Hilty's Environmental systems perspective; see Appendix A).

The Ethics cluster, C5, is rooted in propositions provided in the Genetics (Franke), Ethics and the digital (Kirchner \& Dowes), and Sustainable development (Grunwald and Renn) perspectives (for the perspectives, see Appendix A).

Finally, there is a multirooted Governance cluster C6 that refers to propositions on Big Data analytics (Parycek and Viale Pereira) that stress cybersocial systems and resilience governance, digital-based democracy (referring to Helbing and Klauser), and manipulated democracy (referring to Renn and Grunwald's proposals) as one root and a renewal of the economic (Schuh and Prote) and capitalist system (Helbing and Klauser) as a second root.

Figure 4 presents clusters of the items used in rating the 31 unseens used for classifying the clusters. These clusters can be interpreted as main properties used to describe, characterize, and appraise the unseens. Thus, Figure 3 presents common aspects that are inherent in clusters of unseens, whereas Figure 4 presents common aspects in the concepts used in the science expert's items for judging similarities. The latter may help to provide a bigger picture or even to approach a thick description [57] of the sociotechnical dimensions of digital transitioning as they are seen by European science experts.

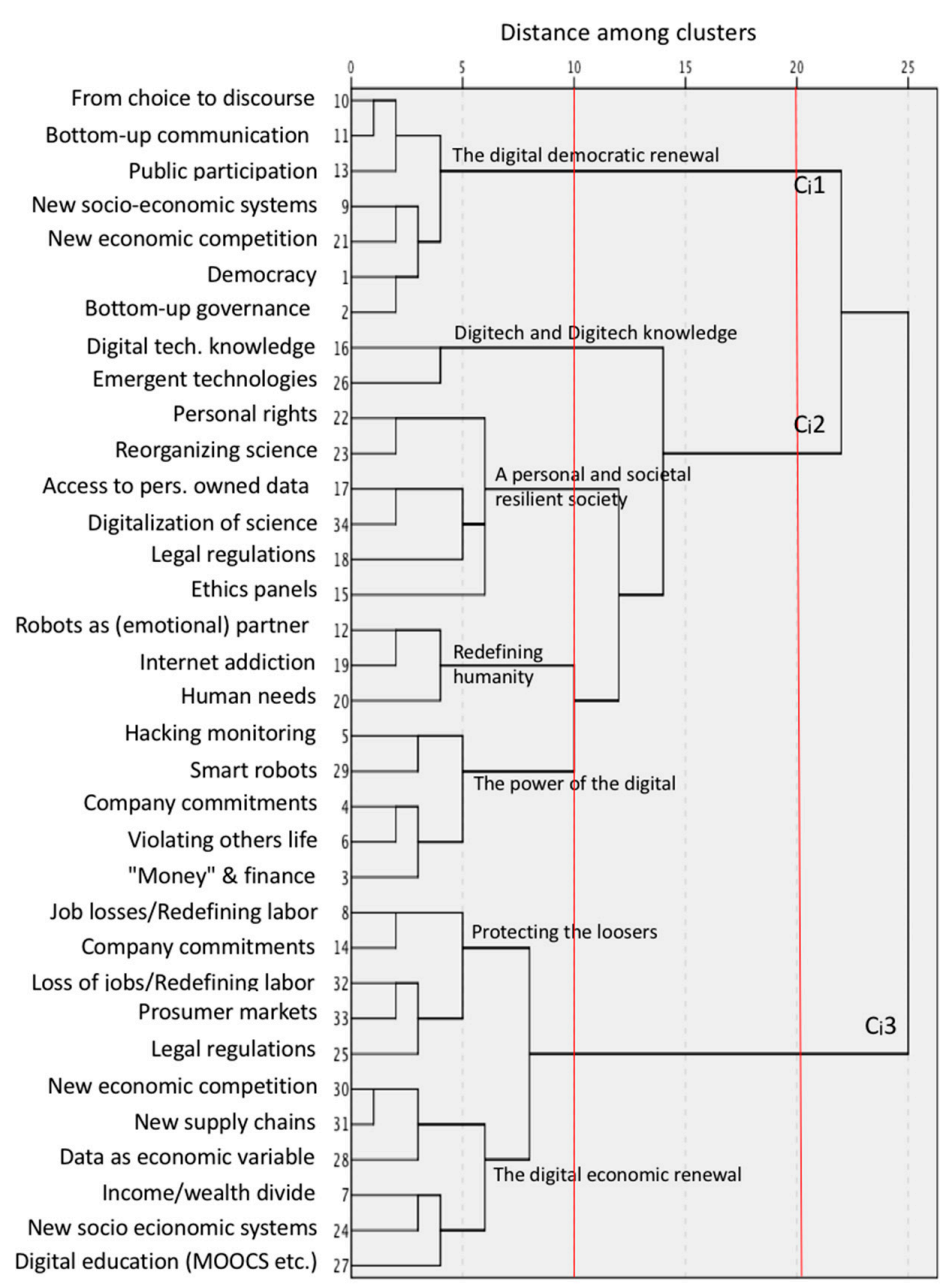

Figure 4. Clustering of the 34 items (left column; the cluster index i refers to clusters of items) extracted from the 31 propositions on unseens. 
Here, we may distinguish three superclusters (with high distance) and seven clusters on a lower level. $C_{i} 1$ (the index $i$ refers to item) denotes the digital democratic renewal, which supplements the lower sub-cluster of $C_{i} 1$, i.e., the digital economic renewal. These two changes may be seen in relation to redefining humanity due to the power of the digital, both sub-clusters of $C_{i} 1$. Finally, we have to acknowledge that $A$ personal and resilient society (sub-cluster of $C_{i} 2$ ) calls for protecting the losers.

\subsection{Results from the Living Pinboards}

The results from the pinboards are an interfacial element between the Propositions (that were written and available before the ERT) and the Main messages that were composed directly after the ERT. The inputs of the experts were put on "keyword buttons" that were grouped by a collective grouping dialogue among all $(N=10)$ experts who participated in this final activity of the ERT.

With respect to 1: Priority list of unseens, the pinboard had four clusters including the keywords ( $N=8$ experts provided input to this pinboard):

- The role of data/knowledge in economics, data ownership, value of data, data economy, rules of using data, methods of aggregation, and transparency of global infrastructure $(N=4)$

- Ethical questions, redefining humanity in the coupled human-digital tech age, the digital reality shift, human autonomy vs. autonomous technology, save human autonomy, externalization of control $(N=4)$

- Urban/regional structures, future of urban life effects of productivity, energy, and climate $(N=2)$

- Experiments, fasten interdisciplinary research

Inputs to 2: Blind spots and overarching layers were provided by $N=6$ experts. The grouping included the following topics:

- Normative reference frame, normativity, timing of tech development, understanding between digital and analog

- Who decides on facts and truth

- Changing the demands (more critical)

- Power distribution

Inputs to 3: Blind spots and overarching layers (for cross- and interdisciplinary research) were provided by $N=8$ experts. Here, $N=6$ experts provided inputs with the following groups:

- Data theory and governance, making data computable, making data understandable, data $=$ past-losing future, data algorithm human interaction

- Power of algorithm, algorithmification

- Power distributions, compare scenarios, the purpose of decision-making

- Time relations, use of time, space, and resources

- New modernization theory, tetrahedron of digital age, level of system organization

No single input was provided to Pinboard 4 (see Supplementary Material 2), i.e., on the question of which stakeholders would be interested in a transdisciplinary process on which topics.

\subsection{Main Messages Constructed Directly after the ERT}

Based on a preliminary analysis of 42 propositions on 10 perspectives, a one-day ERT in Bonn on 19 September 2017, with 11 experts representing eight perspectives, the inputs to the Living pinboard, and continuous interaction based on the goals of the workshop, the first author and André Reichel (a participating discussant of the ERT) composed the following 10 messages. The list of Main Conclusions (MCs) was sent out on 3 October 2018. All 11 participating proposal writers were asked to provide feedback within one week. Based on written and oral feedback by 7 experts, the final version shown below was composed on 17 October 2018. 
Data ownership (see Box 1, MC 1) and, with somewhat minor importance, the relationship to The nature of algorithms (MC2) were placed at the top, due particularly to the dynamics of the discussion and the inputs to the living pinboards. The tremendous changes of a globally Networked, AI-driven, adaptive industry and economy were addressed in MC3.

The DNA personality (MC4), access to the most personal data, DNA (including the option to change this code by nano-engineering) played a special role in this discussion.

MC5, the different Speeds of transitioning, and MC6, Change of human-environment transitioning, stress the new stage of human evolution and the severe challenges of adaptation that human systems have to face related to the digital transformation. The multiple negative Rebounds or unseens, MC7, are an important issue here.

The last three issues dealt with the cross-disciplinary, overarching nature of digital transitioning. These deal with the question of whether MC8, AI, is a means or ends and MC9, whether Innovation is not good per se, and our need for a thorough, interdisciplinary understanding of the Digital Age.

Box 1. Main conclusions (MCs), highlights, messages, hot spots, and lessons of the ERT on Sustainable Digital Environments.

MC1: Data ownership: The most essential point involves data, their ownership, and their value. This may induce a new form of data economy where disembodied data might come to be seen as a new economic entity of the quality of capital, labor, or natural resources.

(We should note that the discussion stressed that we are currently facing a data oligarchy which is far from data democracy. Further, Some ERT members stated that digital data and systems such as Google may be considered as public good.)

MC2: The nature of algorithms and control systems and their unseens: The role of algorithms in different types of computers (including) biocomputers and control systems (which may include human decision-making in different manners) is essential. The type of algorithm (e.g., how an autonomous car functions and how it is directed) will strongly affect individual and social behavior and may cause unseens.

MC3: Networked, AI-driven, adaptive digital industry: Global industry becomes a computer-networked, AI-driven, data-based, IT security-sensitive system that can adapt flexibly to consumer (market demands) needs. The emergence of digital (blockchain, sharing-economy, bitcoin-like) economies of different kinds may become an even more substantial basic layer than the energy ([58]; yet the energy rebounds described by O'Deyer and Malone [58] are of high importance, the last year Blockchain energy consumption was equivalent to the energy consumption of Ireland) transportation, or analog communication layer for the Industrial Age.

MC4: The DNA personality: Data from the genetic sector are the most sensitive. Correlations between (tremendously cheap) DNA profiles and disease prevalence for health insurance or DNA-based intelligence properties for employment can be considered a starting point. The challenge is who will have access to such data, what ethical rules will be applied to handle the data meaningfully, and by what national or global rule systems/conventions this might be governed.

MC5: Speeds of transitioning: Different speeds of revolution: We are facing two transitions: (1) The digital, which is a fast (techno-social) one with severe impacts to society; and (2) a slow one to a sustainable form of living (proposed by Grunwald and Renn, sustainable transitioning or the "grand revolution").

MC 6: Change of human-environment transitioning: The relationship between humans (i.e., human systems such as the individual, groups, companies) and their natural, technical, and social environments will change in the Digital Age. The digital world will function as a kind of moderator (i.e., a digital curtain). This causes what has been called reality shift (this idea emerged already in the Japanese ERT; [31]). This means that the (partly biased, individually shaped) digital curtain is providing a new disturbance variable and distractor for sharing common experiences and knowledge. Socio-materialism (or socio-data-materialism) emerges from the imbrication of the social (policy making) and the material (data inputs) that become entangled within time as people imbricate their agencies towards data-driven decision making process.

MC 7: Efficiency rebounds: Automatization by digital means is providing more-efficient resource management. This, in turn, may provide an increase of material flows, especially when material consumption of digital technologies (finite precious and rare earth metals) and the ecological side effects of material extraction are taken into account. Given the decreasing resilience of ecosystems, this calls for strategies and incentives to avoid negative environmental rebound effects and circular economy initiatives for digital technologies. 
Box 1. Cont.

\begin{abstract}
MC 8: AI, means or ends: There was a dispute during the European ERT on the topic of whether data/evidence-based, simulation-based, automated decision-making based on digital worlds might become real and in what domains this might take place. The question is whether computer algorithms might include context, complexity, human values (instead of current human opinions), etc. in a manner similar to humans, who have a biological organismic nature. In order to better understand the potentials and limitations within AI development, it appears to be important to understand AI not as a singular phenomenon but as being embedded in a hybrid environment of digital representations and algorithms and human agents constituting a new coupled cyber-social world of AI-just as there is no singular human individual but always a close network of human individuals and their social as well as cultural environment that makes them human in the first place. Furthermore, there is a strong need to develop digital environmental literacy in the sense that science and society discuss whether AI-driven decisions are conceived as a means or as an autonomously operating servant of smart/sustainable decision-making.
\end{abstract}

MC 9: Innovation is not positive per se: The question that any technology innovation is positive has been doubted. Human will, needs, and prospects are essential to consider. In addition, the terms "intended" and "unintended" have to be considered in this context (who intends what).

MC 10: Conceptual understanding of the Digital Age: If the double transformation of digitalization and increased sustainability pressures is to be taken seriously, existing modernization theories of how societies are structured and react to rapid change (such as Beck's risk society, White's network theory, or system theories from Luhmann) need a new conceptual foundation. New approaches must take into account the interconnection and co-evolution of human individuals (bodies and minds), technology, society, economy, politics, and culture.

\title{
5. Discussion
}

The discussion first refers to the propositions as a major element of the ERT. The clusters of unseens are first assigned to levels of human systems (Section 5.1). Then (Section 5.2), based on the CLA, we sketch salient overall changes and features in view of the European ERT (Section 5.2). We then (Section 5.3) turn to prospective action and refer to the messages of the living pinboard and the major conclusions identified directly after the ERT. Section 5.4 reflect on the strengths and weaknesses of the presented method of Proposition-based ERT. We end with some considerations on whether the digital transitioning is a stage of technology development (such as the invention of the automobile) or is of more fundamental nature.

\subsection{Unseens on Different Levels of Human Systems}

There is much concern and literature on certain unseens such as the loss of privacy or the loss of full employment by the digital transitioning. The former is a key issue of the individual, whereas the latter is a matter of economy and thus (also) of primary interest on the level of society. We will subsequently discuss what unseens have been identified by the European science experts above the level of the individual and then deal with levels above the individual.

\subsubsection{The Human Individual}

The loss of privacy and the finding of means of protecting privacy have been addressed in a couple of propositions (governmental means [A.6.2 and A.6.3], A.7.5 and A.10.2). The arguments cumulate in the statement that "mass surveillance violates the human right to privacy and it is form of cyberattack" (A.7.4). In addition, the benevolent and malignant, nudging based on personal Big Data as well as the coping with individually tailored fake news (see A.10.2), i.e., knowing whose information you may trust and believe in is a new challenge in the individual's life, are included in the propositions.

From a psychological perspective, unseens of digital technologies were assigned to the psychoneurological sensitivity (see Figure 3; Cluster C2) of the human individual. Humans show limits in multitasking (e.g., solving a challenging problem when simultaneously responding to the e-mail alert). The spreading practice of being ubiquitously accessibility at any times for different issues is one reason of the fragmentation of life (A.4.2). This often results in loss of efficacy and efficiency and affects well-being. 
The new digital etiquette (A.4.2) with others and the environment is increasingly patchy, disintegrated, virtual, and indirect interaction that does not allow for an empathic trust building or reliable judgment on the partners intention and preferences. This may be also relevant for the interaction between policy makers. For instance, some politicians switch from personal, empathy, mutual trust building- and partnership-based verbal (e.g., telephone-based) interaction or physical interaction to twitter short notice. The personal relationships (see Appendix A.4; [59]) resulting from a virtually shaped interaction factually differs from those when interaction with the human personal.

There is an evolutionary new form (e.g., two-dimensional screen-based pictures vs. a complex, co-evolutionary developing environment such as a complex tropical forest), density, artificial, and increasingly virtual (and thus evolutionary unknown) information. We may take from anthropology and human history that human is a highly adaptive species that may adapt to physically and socially highly different environments. If the digital environment does not meet the primal emotional needs (see A.4.4) human health and well-being may be endangered. Addiction, epigenetic and other measurable biophysical effects may result as unseens $[4,59]$. Interdisciplinary research and monitoring on health impacts of e-sports [60] seem to be necessary. Interdisciplinary research on monitoring and transdisciplinary processes including key actors on health impacts of e-sports seem to be necessary.

The access to the genetic code provides another critical unseen. Assessing an individual's DNA costs just about US\$30. And there is increasing knowledge to judge the risk for certain diseases based on the DNA data and a most recent paper in Nature Reviews Genetics confirms the concerns expressed in MC6 (Box 1). Some countries (such as Switzerland or The Netherlands) are going to prepare laws which allow or even demand health, life, or disability insurances to ask for DNA and adapt insurance costs to the DNA profile (A.5.1). Genetic privacy, perhaps the highest-level privacy, seems to be in conflict with severe economic and other interests. Given that the 193 countries that are members of the United Nations (and inner country federal state laws) differ essentially, this case shows that global regulations are needed to protect the individual. The importance of this issue is stressed by a recent review. Large scale studies including more than one million subjects show that " $20 \%$ of the $50 \%$ heritability of intelligence" can be predicted by genome-wide polygenetic scores.

\subsubsection{Human Groups}

Small groups build a primary evolutionary entity which forms the individual personality of humans [61]. Group norms, goals, hierarchy structures, decision rules, rewarding and penalizing behavior, rules for being a member etc. $[25,62,63]$ and the identification and differentiation of groups have been an essential part of socialization in all cultures. Internet groups show similarities and differences [64] which may be beneficial and negative for certain type of people and for different purposes. Diversity of information and expertise among group members has been identified as a crucial ingredient of collective intelligence.

There is a basic interpersonal need to belong to a group whose members share interests, values, etc. On the digital web, there is a large scale of online groups, chat rooms, etc. which allow to build virtual groups or well-organized digital heterogeneous communities across the world [65]. Critical unseens may emerge from overcoming loneliness, (different forms of honest, positive). This may lead to self-disclosure [66] which is misused when personal data are transmitted by others to the public.

\subsubsection{Organizations (Companies)}

The propositions just focused on commercial organizations (i.e., companies) ranging from industry, via various forms of Internet companies, to financial institutions. Unseens for noncommercial organizations have not been considered.

Much focus has been given to changes related to production. The governmental German Industrie 4.0 initiative promotes the aggregation and synchronizing of data and processes on different levels of manufacturing and production (A.1.1). This increases efficiency along the supply chain. Yet, allows for 
new risks of industrial espionage and data security. The factor knowledge and data become a new critical entity also on the business level (A.2.1). A new, digitalized and networked supply, for instance, may endanger valuable technical know-how of small and medium sized industry. Thus, in order to become negatively affected by the digital transformation, the given case SMEs should develop strategies that help to decide what digital technologies should be introduced when to keep the viability of the enterprise. This vulnerability assessment is factually subject of a recent method that has been applied already to many companies [40].

\subsubsection{Institutions (Governmental Organizations)}

Public services are becoming digital. There is a trend on automated decision making based on Big Data of the residents and the cities. The "war against drugs," terrorism, etc. promotes the storage of large personal and economic data from residents, companies, political actors, etc. Following the European democratic principles, unseens may emerge from various sources: (i) Often, the roles, actors, and data owners are not clearly defined (A.6.1); (ii) data may become accessible to semi-public organizations or other countries whose legal regulation and data are collected; and (iii) data security may be questionable given the large number of public servants working on data to establish resilience digital data governance models (A.6.3). Viale Pereira and Parycek (Appendix A.6) stress that not only a responsible use of public data but also the relations of the citizens to algorithms may cause problems and ask for regulations.

\subsubsection{Societies (Nation States)}

Digitalization will change the main components of society (i) economic system; (ii) political and legal system; (iii) the social and cultural system; (iv) scientific and educational system $[25,67,68]$.

Platform economics (A.1.4), global customer driven production (A.1.3), knowledge economy (A.2.1), home offices and new forms of freelancing (A.3.3), AI driven machines (A.7.5, see also MC8), crypotoeconomics (A.9.2, targeting a decentralized economy without political structure, legal system, geographic location [69]) and the increasing role of (digitalizable) knowledge (A.2.1), virtual products etc. will generate new economic structures, agents, and processes.

Strong impacts have been expected in the fields of public governance (see Section 5.1.4) and politics. In politics, unseens are related to Big Data analytics-based nudging (A.10.2) that calls for careful attention.

Culture has only been addressed by digital etiquette (A.4.5) on the level of the individual. But, the behavioral change on the level of the individual and small group is transforming interpersonal communication, trust formation, etc. as components of societal culture will fundamentally change [70].

The unseens with respect to the scientific and educational system have been addressed in the context of ethics (A.8.2). Digital representations and digital technology fundamentally change the whole scientific system. This goes beyond the world wide web-based real-time interaction among scientists, measurements etc.

\subsubsection{Human Species}

Many of the identified unseens address the level of the human species. This relates to

- the fundamental redefinition of human labor which asks for new forms of higher knowledge resulting in a new form of digital divide including a potential loss of what is conceived traditionally as labor (A.1.2, A.2.3 and A.10.3)

- the emergence of (digital) knowledge economy (A.2.1) when (digital) knowledge (and data; i.e., digitalized labor; A.2.2) supplement capital, labor, in this context also surveillance economics in which personal data are of economic value may taken as example [71], as suggested by one of the reviewers of this paper, digital technology may be conceived as an affordance to which any economic transaction has to adapt 
- new forms of property rights are required to avoid economic imbalance as both the self-learning AI machine and the data provider contribute to new knowledge and economic values (A.2.4)

- efficiency rebounds result by hedonistic, amenity value driven demands ( A.3.1 and A.8.3)

- digital (intentionally resilient) public governance [72] and democratic capitalism (A.9.3) which may, however (in a critically long transition period (A.6.1 and A.6.2)) be endangered by deceptive, antidemocratic and self-enrichment oriented cyberattacks, and

- cyberwar on all levels of human systems, ranging from the individual to global networks of people and countries (A.7.2)

Admittedly, this set of examples rather refers to the darks side of possible developments. And they are in contrast to the often positive, sometimes enthusiastically optimistic visions expressed in many propositions. But this, vulnerability shaped view on unseens may be conceived as an important means of resilience management. We may also incorporate the proposition of the first author presented at the Japanese ERT on various vulnerabilities related to directed evolution (of plants, animals, and humans) by the mastery of genetic engineering (see B.5.2; this has been expressed by a European participant). Finally, the change of the science system by using digital technology for recording data, communication among scientists, fighting plagiarism and fraud in data fabrication, automated scientific discovery (e.g., by AI-program-based planning of sequential experiments), computerized mathematical proofs causation (see A.8.2) has been mentioned and discussed. Yet, naturally, the before-mentioned issues are incomplete, also as certain perspective were missing at the European ERT.

\subsection{Developing a Bigger Picture on Major Unseens}

The development of a bigger picture is done when summarizing the major communalities among the unseens (Section 5.2.1) and when relating the major conclusions (see Box 1) of the European ERT (Section 5.2.2).

\subsubsection{Clusters of Unseens and Common Patterns in Ways of Evaluating Unseens}

Both, the middle clusters of Figure 3 Smart factory, labor market and justice (C3) and Economic change and rebounds (C4) indicate that the ERT considered production and economy as an important domain if not as kernel of the digital revolution. However, as indicated in the label of C4, besides changing the economic and the financial systems (which may include specific unseens), environmental rebounds build another sub-cluster. Cybernetics and warfare (C1), which include unseens related to data security (as the concept of war requires some redefinition; A.7.1), are related with regard to content. The ambiguous, double-edged sword nature of the digital transitioning, which is characteristic for any technology innovation, is ubiquitously visible.

The neuropsychological sensitivity (C2) has been mentioned on the level of the human individual and (small) group. But technology has been a key factor of the cultural evolution all along the history of humankind, human life will look like different after the digital transitioning than before. Certain domains of the mind and the body will be trained and developed in a more pronounced way.

Finally a proper digital technology-based society asks for new forms of governance (C5) and ethics (C6). Ethical dilemmas linked to learning machines (A.8.5) may call for new ways of looking at humankind.

\subsubsection{Overarching Aspects of Interdisciplinary Research (Goal 2)}

The clustering of the main properties used to classify the unseens provides quite a comprised picture. We may conclude that the power of the digital, based on digitech and digitech knowledge is promoting (i) a renewal of the economic system and (ii) launching a digital democratic system. There is concern with respect to (iii) protecting the losers of the digital transformation, particularly approaching a personal and societal resilient society in a fundamental process of (iv) redefining humankind that calls 
for basic philosophical, ethical, and epistemological questions of general interest. The identified as subjects may well serve as overarching aspects for restructuring research (Goal 2).

\subsection{Additional Results and Follow-Up Activities from the Proposition-Based Science ERT Discussion}

The above discussion much focused the proposition. They were individually prepared by the experts when relying to their perspectives and disciplines. But what new outputs and perspectives emerged from the interaction among the science experts. What has additional views developed across the perspectives (see Sections 4.2 and 4.3). What topics for transdisciplinary processes have been identified? (Goal 3)

When referring to what has been discussed before, the following additional issues emerged from the ERT:

The economic value, ownership, access and use of data including data theory and governance, has been discussed in depth (MC1). This discussion has been related to control systems, transparency, and ethics of algorithms that govern data processing in an increasingly automatized, AI-driven digital world (MC2). Thus, in terms of Table 1, the understanding, praxis, and management of the basic elements of digital technology, the storing, retrieving, and transmitting digital data and the processing-i.e., the application of algorithms (see also A2.1, A6.1, A6.4 and A8.3) raised special concerns. In this context the discussion on how to deal with DNA data (MC4) raised special concern. We may think that this issue may become a global learning field for rethinking how privacy may have to be reconsidered.

Somewhat surprisingly, as transdisciplinarity processes were demanded in A10.4 and during the process, there have been no direct inputs on topics that may become subject of transdisciplinary processes (Pinboard 4). Yet right after the ERT the idea emerged that private, commercial, and public agents may be interested to reduce the vulnerability and to increase the resilience of the global digital world. This may include the identification of loopholes in the global legal system, weaknesses in the implementing executive control of legal regulations (such as the Amendment of the European Data Protection Regulation [73]), to focus critical issues such as privacy by design, to identify (ongoing potential) deficient behavior of actors (and to develop strategies to cope with this) by relating the knowledge of key representatives from key stakeholder groups with that of scientists working on sustainability and digital environments (SDE). The objective of the transdisciplinary process (which is under planning by the Institute of Advanced Sustainability Studies, IASS Potsdam Berlin, and right refers to MC1) include of self-declaration of key stakeholders on responsible data use and the draft of ethics principles from a practitioner and a scientist perspective.

Two-more theoretical-insights not yet included and the proposition (discussed above) deserve mentioning. One is on different speeds of change of technological, socio-cultural, and biotic-genetic systems. We think that this issue asks for a thorough reflection, in particular when proper means of mitigation, adaptation, and interventions (as not any innovation is positive per se; MC9) are targeted. Another refers to the new evolutionary dimension of AI, which alters the human-environment relationship, introduces socio-digital/material systems. And thereby calls for a thorough, reflexive understanding of the Digital age (MC 6, MC 8, MC 10.).

Finally, the European proposition-based science ERT on SDE has been considered that the seminal way to structure the changes and unseens from different disciplines. Thus, the initiators of the Japanese and the European ERT will launch further ERT to support a resilient digital transitioning.

\subsection{How Do the Japanese and the European ERT Differ and Complement Each Other?}

The Japanese ERT also focused on the potential unseens of the economic transition, such as platform lock-in by the oligopoly of platform providers (B.1.1) and AI-induced underemployment (B.7.1) or low-capability franchise workers, which can result in a new stratum of the poor in a society. Although some participants had backgrounds in political science, the changes to democratic systems (though mentioned in one proposition referring to Internet monopolies; B.4.1) have not been in the foreground as much as they were in the European ERT. 
Much attention has been given to risk management (B.3.2 and B.6.1), in particular to black-swan risks, e.g., new systems of digital risk resulting from the interconnectedness of an IoT world. Here, the threat that one monopolitical enterprise may stockpile all intelligence has been seen as a potential unseen (B.4.1)

With respect to the individual, the imperialistic spread of US-Western culture by the Internet (B.2.2), i.e., the reality shift caused by individually shaped, biased information channels that are not corrected by "evolutionary feedback loops" (B.1.2), have been named in a pronounced manner. Finally, biotechnological governance (B.5.1 and B.7.2) based on the management and engineering of DNA and biocomputers as a new form of cognitive, hybrid decision-makers (see 1.4 above, B.5.1, and Appendix B.1) was mentioned.

The cultural differences have been presented earlier in 1.4. One of the Japanese experts stressed that the apocalyptic concerns shared by many Western authors about technological singularity, where a future superintelligence substitutes for and suspends humankind, is not shared by many Japanese. In line with this difference, in Japan there is a much stronger desire among experts and the public "to co-inhabit with AI and robots" [31] than there is in Western cultures. The role of religion and worldview, here, that of Shintoism and Confucian thinking regarding the preference for humanoid robots, has been explained in 1.6 as the differing understandings of the role of academic knowledge in transdisciplinary processes. Transdisciplinary processes have also been recommended by the Japanese ERT. Yet, whereas in Europe transdisciplinary processes generally include both representatives from key stakeholder groups (e.g., of people concerned) and representatives from different scientific disciplines on an equal footing, according to Confucian thinking and practical order, those who are expected to know (i.e., academia) should take the lead.

\subsection{Constraints of the Method of Proposition-Based Expert Round Tables}

Round tables are a common means of looking at one and the same issue from different perspectives. A round table, such as panel discussions, allows a certain set of invited people to exchange, discuss, supplement, explore, examine, question and to (gently) verify certain views on an issue. From a methodological point of view, we used the ERTs as a means of triangulation for better understanding and ranking unseens and the ways in which science and transdisciplinary processes may serve to deal with them properly. We should note that not only the content has to be triangulated. This has been done in the present case by perspectives. In order to develop socially robust orientations, Triangulation should also refer to disciplines (and the included modes of validation; this has been), worldviews, philosophy of science perspectives, and other issues. The exceptional broad scope of disciplines (including natural, engineering, social sciences and humanities) has been promoted by the choice of the perspectives.

But the presented ERT went beyond an ad-hoc single meeting round table as it included elements a Delphi-like multistage process [74]. Experts were asked to present (proposition on the) the most important unseens from their own perspective and the initial input was evaluated and adjusted in form and content after feedback of the organizers of the ERT. All experts gained in-depth insight into other experts' views and referred to a set of definitions of key terms that were included in a jointly shared and produced workbook that included the propositions. After a full day of listening to each other, the main impact factors and features of unseens, missing knowledge about them, and suggestions what issue may be better understood by science were discussed (see above the living pinboard technique). And, based on an in-depth cluster analysis, the main domains of society and common features of the ERT were identified. A preliminary analysis using these methods was also used as input for formulating main conclusions which much resemble the aspiration of policy Delphis to obtain reliable orientations [75] before decisions are taken.

If we think about the critical, biasing, artefactual side of the chosen methodology attention has been paid to questions such as: Are proper goals and questions to be answered by the (right things) properly addressed? Is the set of perspectives addressed by the right experts well 
chosen? What experts, with what expertise, cosmology (including philosophy of science perspective) or with what self-conception as scientist (e.g., public good vs. advocacy) are chosen? We will just answer the last question. In autumn 2017, the discussion on Europe was not formed by a single special event (such as the Facebook-Cambridge Analytica case, March 2018) that affected the ERT. There, public media at that time were much shaped by discussions on deliberate computer attacks and nudging of citizens in the course of elections.

\section{Conclusions}

Taking ten different perspectives, seventeen European science experts provided forty-two propositions on unintended side effects (unseens) of the digital transition. Based on this carefully deliberated and written input, a full-day exchange about features, sources, critical developments, intersecting issues, and potential transdisciplinary processes was achieved. The written inputs, the round-table discussion, and the follow-up content analysis (based on cluster analysis) resulted in an interactive, structured (Delphi-like method) method, which we call a proposition-based expert round table. The application of the method allows for the following conclusions.

Digital technology, conceived both as the knowledge about and the physical manifestations of digital technologies, induce, first, a most fundamental renewal of the industrial and (capitalist) economic system. The intangible, potentially non-scarce, and (principally) ubiquitously accessible asset "digital data and knowledge" is supplementing capital, labor, and natural resources and altering processes and restructures of the supply chain (e.g., by IoT based production and platform economics). Likewise, second, (an infrastructure-like) digital public service and democratic system are developing. We should note that inner science unseens (such as dealt with in Appendix B.1) have not been subject of the European ERT.

Like any technological transition, the Digital Revolution is a double-edged sword. Thus, special attention has to be paid to unseens. The European ERT argues that, third, protecting the losers of the digital transformation is a major challenge on the pathway to sustainability; losers here refer to people, companies, and other human systems that cannot (sufficiently) adapt to digital economic processes. Here, individuals and human groups that show sensitivities with respect to critical issues (e.g., internet addiction in various forms) are one example that requires more attention. But in addition, the subtle, individually biased, or even manipulated information and nudging processes that endanger the very foundations of democratic processes call for better understanding and counter-strategies. Thus, ownership, economic value, use, and access to digital data are key steps on the way to a personally and societally resilient digital society. The (market) value of personal DNA data may play a special role in the future (see Box 1, MC4). What route will be taken here much depends on the decisions (and behavior) of policy makers, industrialists, and individuals.

The process of substituting cognitive processes with AI-based digital technologies is presumably the most fundamental transition in sociocultural human evolution. This is indicated by the landmark idioms redefining labor, democracy, or humankind. The natural, technical, social, and humanity sciences are challenged to contribute to a better understanding of fundamental questions referring to data governance and potential, and the limits of algorithmification; the essence of digitally shaped biotechnological systems and engineering as well as bionic systems; various forms of vulnerabilities of natural and human systems; and the roles of religion, ethics, and culture as prerequisites for understanding and forming the Digital Age. These issues, on the one hand, call for integrated, cross-disciplinary, and interdisciplinary research supported by the frame of sociotechnological vulnerability and resilience analysis. On the other hand, societal-sustainability learning may be supported by transdisciplinary processes in regard to certain complex unseens whose understanding and management call for utilizing experiential expertise from practice and sound, high-quality scientific knowledge from different fields of science. We are convinced that science-expert roundtables such as the European and the preceding Japanese one may help pave the road to a more sustainable future. 
Supplementary Materials: The Supplementary Materials I and II are available online at http:/ /www.mdpi.com/ 2071-1050/10/6/2001/s1.

Author Contributions: This expert round tables have been planned by R.W.S., P.P. and G.S. (Gerald Steiner). All authors (besides A.R., R.W.S. and G.S. (Gerald Steiner)) participated in the proposal writing. E.J.B., S.D., L.F., A.G., L.H., M.H., S.K., C.M., P.P., J.P.P., O.R., A.R., R.W.S. and G.V.P. participated the expert roundtable. G.S., G.V.P. and R.W.S. worked on the content analysis of the propositions including the Cluster Analysis. The first draft of the manuscript was written by R.W.S., then modified and supplemented by A.R. and G.V.P. All authors read the complete draft and provided feedback and inputs to previous versions of the submitted manuscript and agreed on the final manuscript.

Funding: The European Round Table on Structuring Research on Sustainable Digital Environments received funding from the German Federal Ministry of Education and Research (BMBF), Berlin.

Acknowledgments: We thank Gabriel Lentner for his feedback and Elaine Ambrose for the thoughtful English language editing and four anonymous reviewers for their valuable and inspiring feedback.

Conflicts of Interest: The authors declare no conflicts of interest.

\section{Appendix A. Propositions on the Future Perspectives on Digital Transition}

Appendix A.1. Propositions on "Industrial Change:" Günther Schuh and Jan-Philipp Prote

\section{A.1.1. Industrie 4.0 as enabler for cross-domain collaboration in industrial practice (Proposition 1. Cross Domain collaboration and Industrie 4.0 security challenges)}

Industrie 4.0 will enable a new level of cross-domain collaboration within producing companies, facilitated by exchanging and using information from production, development and the user experience in real-time and on an adequate level of granularity.

Comment: Industrie 4.0 allows for aggregating and synchronizing data from a highly application related granularity level (e.g., MES-, ERP-, CAD-data) to enriched smart data for multi-domain-use [76,77]. Having created such a multi-modal information access, companies will be able to develop smart expert systems that serve as a cross-domain decision support for complex decisions reaching from development over production to usage of products [78,79]. Examples for those complex decisions are an allocation of products in a global production network, an automated generation of work plans, or an efficient and effective handling of change requests generated by changing customers' requirements. Consequently, cross-domain decisions can be made significantly faster and in higher quality, leading to a competitive advantage by sustainable cross-domain collaboration. In order to ensure the sustainability of the cross-company collaboration and to secure that added value is allocated according to the input factors of the different shareholders in the supply chain, special rules for allocation might be necessary. In addition, special attention has to be paid to security matters and it has to be defined how and in which form data can/has to be shared to avoid industrial espionage and know-how loss.

\section{A.1.2. Change of qualification profile (Proposition 2. Redefining labor (qualification))}

The qualification profile of all hierarchy levels will change requiring more IT skills, a profound and fast understanding of complex decisions and interdisciplinary knowledge. Especially interdisciplinary skilled IT specialists, who are able to use their IT knowledge in the respective system context, are needed. A manager's or specialist's working time will have a higher value-adding share by less actively searching for information but more evaluating information for process and product innovations. On the other hand, less qualified employees will be enabled by IT solutions to perform (more) complex tasks.

Comment: Today, employees need to spend a high value of their working time on "waiting and searching" for information. In future, Industrie 4.0 is expected to dramatically decrease this share by actively analyzing and preparing information on large scale and (almost) real time, highly aligned 
to the employees' need. This change has major consequences on the qualification profile of the respective workers.

Blue-collar workers on the one hand will face an increase in guidance for their work, associated with faster and data-based decision-making on the shop floor. This requires an intuitive understanding of collaborating with information systems. White-collar workers on the other hand will be relieved of analyzing data as computers have a huge advantage on this task but will have to process information as a result of the analyzed data in larger quantities and in more dimensions. Thus, interdisciplinary qualification will be a basis for getting a profound understanding for complex decision. Nevertheless, to include all different employees in the future industrial change is one of the bigger challenges of the digitalized age.

\section{A.1.3. Customer-driven, agile product development and production of goods (Proposition 3. Customer driven production)}

Not only the agile product development will become aligned to the individual customer needs and requirements. Also the production process no longer "prevents innovations", but is fast adaptable to any kind change in the customer needs and thus product specifications.

Comment: Traditionally the customer's needs, opinion and experiences are only partly involved in the development and the production planning process. Therefore, the mostly longstanding process was often hardly adaptable to any kind of change in the customer's needs. To handle those uncertain requirements in today's volatile and changing market environments an agile product development and an agile production are inevitable $[80,81]$. The customer should be effectively included in the process and quick early-stage-prototypes should be used to test functionality and customer satisfaction. By distributing the development in short and iterative sub-processes, so-called sprints, the agile product development integrates all changes in customer requirements and thus the customer itself. Those changes also highly influence the production cycle, where a fast implementation of all change requests will be possible due to the cross-domain collaboration in the company based on Industrie 4.0. Thus, the whole company will become more and more customer-driven affecting all domains. However, since the agile approach is fundamentally different to the existing methods, special attention should be paid to avoid outpacing part of the workforce or the loss of efficiency in the system. In order to secure the latter coordination and synchronization of development and production processes becomes even more important.

\section{A.1.4. Development of innovative business models (Proposition 4. Platform economics)}

Industrie 4.0 offers huge opportunities for conventional companies as well as new players to evolve and create new business models using new digital solutions and services. Existing customer needs can be satisfied more efficient or new customer needs can even be created.

Comment: Industrie 4.0 allows new perspectives on existing business models and the exploitation of entirely new business areas partly substituting traditional business models. New products are possible to build, but also new companies, often in the IT sector, demand existing or not-yet-existing market shares. For example, shared platforms or clouds for example are created to act databased as an intermediary between the producer and its customer and allow a better holistic understanding of the customer's true needs. In mainly four areas new business models enabled by Industrie 4.0 can be expected. First, products can be enriched or even substituted by smart services, which create a benefit for the customer e.g., predictive services. Second, all gathered data can be refined as smart data to enable e.g., cloud solutions or a web-based data management. Third, the product itself can be adapted and enhanced, to achieve a cyber-physical product. Last, the production engineering can be enriched by digital IT systems e.g., 3D-assembly instructions. All those new business models are a 
possible threat to traditional models and hence are necessary to consider in order to stay competitive. Economic and industrial domains, regions and players which do not master/are not open to think and try out new (data based) business models, are endangered to not participate in the benefits of these new business models and might be outperformed by (new) competitors.

Appendix A.2. Propositions on "Economic Change": Eric Bartelsman

\section{A.2.1. Transformation of Production Technology (Proposition 1. Knowledge economy)}

Digital technology is enabling a rapid increase of the importance of the factor 'knowledge' in the production function used to supply goods and services, and is thereby changing the role of traditional factors land, labor, and capital. The impact of this transformation on the economy may be comparable to the historical shifts from hunting/gathering to farming (land) or from farming to industry (capital).

Comment: The so-called 'Kaldor facts' have guided our theories about long run economic growth, but current observations don't fit the facts anymore. One main observable that no longer seems to hold is the constancy in shares of income going to capital and labor. Production functions with intangible assets and non-constant substitution elasticities between intangibles and capital or labor inputs can help explain the changes in historically observed relations of long-run growth. Further, the transformation also may help explain the increasing dispersion in productivity and profitability across firms or the increasing inequality in earnings across workers.

\section{A.2.2. Changes in demand for tasks (Proposition 2. Digitalized labor)}

Recent theoretical and empirical research on labor distinguish different tasks that workers undertake. As current digital technologies are adopted and new technologies emerge, researchers try to evaluate which tasks are substituted for by the technology and which tasks are complements to the technology.

Comment: The main idea behind the task-based model is to distinguish tasks along two dimensions, namely routine vs. non-routine and manual vs analytical tasks. Current occupations can then be mapped to the types of tasks they require. To find the effects of technology to individual workers' earnings one further needs to know the relationship between worker skills (education), occupation, and tasks. Changes in income distribution can be understood through changes in supply of the ability to undertake tasks and demand for those tasks (changing under influence of technology). In this framework, total employment generally is not affected by shifts in technology, because direct substitution of some tasks is offset by demand induced increases in tasks elsewhere [22,82].

\section{A.2.3. Income Inequality (Proposition 3)}

With the changes in technology, the share of income going to labor and tangible capital decreases while the share for intangible capital (knowledge) increases. Further, the income accruing to knowledge is becoming more skewed to the top earners.

Comment: In traditional economic theory, returns to production inputs rise with their marginal contribution. The returns to knowledge input are more difficult to analyze within the theory, because knowledge is non-rival in production. Once knowledge exists, it is no longer scarce and its marginal cost becomes zero: its use in one setting does not preclude its use elsewhere. Demand will shift to the 'best' bit of knowledge, greatly skewing returns. In case of network effects, the earnings winner need not be the 'best' bit of knowledge [83]. This latter possibility harms the incentives to develop the best intangible asset and instead diverts resources to attempt winning the network. 


\section{A.2.4. Rethinking Intellectual Property Rights (Proposition 4. (Ambiguity of intellectual) Property rights)}

The system for stimulating development of new knowledge and intangible assets through patents, copyrights, subsidies, and prizes needs to be recalibrated for a world with self-teaching robots fed by user and device generated data.

Comment: Much has been written about intellectual property rights and the tradeoffs they generate between incentives for knowledge creation and the monopoly distortions in the use of goods produced with this knowledge [84]. The system does not function well to provide returns to small incremental additions to knowledge leading up to protectable innovation. A new twist to the argument comes when transactional data, e.g., between a physician and patient or from internet-connected devices, gets used to improve the functioning of machines owned and developed by third parties.

Appendix A.3. Propositions on "Environmental Systems": Mattias Höjer and Lorenz Hilty

\section{A.3.1. Macro-Economic (Proposition 1. Efficiency rebounds on environment)}

To the extent that the digital transformation leads to an increase in productivity, society will be forced to either increase demand for the goods produced or decrease demand for human labor, with potential negative impacts on environmental systems.

Comment: Increasing labor productivity logically leads to either increased consumption (a) or decreasing demand for human labor (b). To the extent that society will continue on road (a), the damage to our live-supporting systems by the prevailing patterns of production and consumption will be intensified, unless the digital transformation will at the same time be used to decouple value-creation from resource flows (growth in consumption but not in natural resource use [85]. This can in principle be done by dematerializing products (substituting services for tangible goods and better utilization of capital goods) and by supporting a closed-loop economy, i.e., using intelligent recycling for keeping anthropogenic materials flows in the technosphere and minimizing their exchanges with the environmental systems [86]. To the extent that society takes road (b), the digital transformation could be used to support forms of labor markets and finding new ways of distributing social income.

\section{A.3.2. Contextualizing environmental effects (Proposition 2. ICT-ambiguities)}

Create assessment methods highlighting the importance of context when evaluating ICT.

Comment: Digitalization is changing society. But society is deciding what effects digitalization has on the total environmental effect [87]. This insight is both encouraging and discouraging and more research is needed in developing assessment methods that highlights this. The insight is discouraging since it means it is really hard to come with clear statements regarding the actual effect of an ICT-service $[88,89]$. And it is encouraging because it shows the room for a wise decision. ICT in combination with other measures can reduce resource use and environmental impact. ICT alone may well lead to increased resource use and environmental impact. In order to get a better understanding of how this works, and to get a common language, interdisciplinary work is needed.

\section{A.3.3. Digitalization and regional development (Proposition 3. Restructured region-rural home office)}

Encourage research on digitalization and sustainable regional development 
Comment: Digitalization is changing the way we live, our daily activity patterns. This can be studied and presumably either adapted to or in some way planned for-there are both proactive and reactive approaches to the change. An example of the changes we can foresee: the Swedish telecom operator Telia recently moved some 4500 employees to one and the same office, from a number of previous locations. Meanwhile they reduced office space drastically and introduced entirely flexible seating. The new office is well located from a public transport point of view. An internal report shows that $60 \%$ of the employees have changed their travel mode with the move, reducing car commutes from 57 to $24 \%$ and increasing public transport from 33 to $63 \%$. And new activity patterns are emerging. More people work from home, or from a place near home some days a week [90]. With more people staying in the area where they live during daytime, the structure of the region can start changing. Is this something regions should adapt to? Encourage? Try to work against? And what potential environmental effects can come of this? Telia is just one example. Change affecting regions come in many different ways.

\section{A.3.4. Means and measures for buildings (Proposition 4. Use of Buildings)}

Investigate how we can create new principles and measures for use of buildings, and how digital solutions can support a more efficient use of buildings.

Comment: The Swedish road agency works according to a "four-step principle" when analyzing new investments. The first looks for opportunities to reduce demand. If not enough, they try to increase intensity of current infrastructure use. If not enough, they look at minor complements to the current infrastructure. And only as fourth step, they build new infrastructure. Recently, we suggested a corresponding principle for building: 1 . Reduce demand; 2 . Intensify use of indoor space; 3 . Rebuild; 4. Construct new buildings [91]. The four-step principle can be strongly supported by new measures $\left(\mathrm{kWh} /\right.$ activity instead of $\left.\mathrm{kWh} / \mathrm{m}^{2}\right)$ and digitalization has a key role in creating opportunities for using space more efficiently and thus reduce demand. This has potentially large-scale effects on how cities and regions work and on total energy use in the building stock and for building new buildings [92].

Appendix A.4. Propositions on "Social- and Neuropsychology": Digital Communications and Ontogenetic Development: Sarah Diefenbach \& Christian Montag

\section{A.4.1. HCI as social interaction and self-reflection (Proposition 1. Human robot, technology as social agent and mediator of social interaction)}

Human-machine interaction must be considered as a form of social interaction and self-reflection.

Comment: With technology getting "smarter", taking the role of a conversation partner or making the impression of a living being (e.g., social robots), a central question is to what extents mechanisms from social psychology, describing interaction between humans, apply to human-computer interaction (HCI) and human-robot interaction (HRI) [93]. This is particularly relevant for trust and acceptance of technology use, but also manipulation or unintended side effects. A replication of the classical group pressure Asch-paradigm (a line assessment task) showed that a robot's judgments had more impact on one's own judgments than that of other humans [94].

Another important research question is to what extent technology-initiated routines also shapes self-reflection, self-presentation and the impression one makes on others. Studies on the "selfie-paradox" [95] showed a systematic discrepancy between judgments on own and others' selfies: while own selfies were judged as more authentic and self-ironic, others' selfies were judged as more self-presentational. 


\section{A.4.2. Fragmentation of everyday life (Proposition 2. Fragmented Life (and digital psycho-neuro-dynamics))}

Technological overuse induces a fragmentation of life and Internet Use Disorder.

Comment: Problems arising from the fast developing digital worlds are already visible in everyday (work) life. Constant distraction and fragmentation of our lives due to technological overuse can result in loss of productivity [96]. In addition, one needs to take into account that humans do not excel in multitasking, because they rather process information on a serial compared to parallel level. These principles need to be strongly considered in the design of work places in digital worlds. There is first evidence that dependent on personality structures overuse may cause Internet addiction which asks for therapeutic interventions [97].

\section{A.4.3. Brain research on DMI (delayed memory impacts; Proposition 3. Psycho-neuro- endicrinonogical dynamics)}

There is a need for interdisciplinary psychoneuroinformatical research on epigenetic, molecular genetic and endocrinological processes related to interactions with digital worlds.

Comment: Research in the area of the already introduced topics such as trust, etc. can be enhanced by the inclusion of neuroscientific methods, including epigenetic, molecular genetic and endocrinological approaches. To name a few biological candidates, the stress hormone cortisol can be well investigated in the context of technostress and the neuropeptide oxytocin in the context of trusting artificial intelligence. Finally, brain imaging procedures need to be mentioned, because first studies show (i) that digital worlds might shape our brain functionality (e.g., smartphone usage shape motoric areas of the brain) [98] and (ii) recent evidence demonstrates that individual differences in brain volumes of the nucleus accumbens can predict the use of the Facebook application on smartphones. This field requires a combination of data from psychology, the neurosciences and computer science (real-life behavior tracked at the intersection of the Internet of Things (IoT)) perhaps resulting in a new research discipline called Psychoneuroinformatics [99].

\section{A.4.4. Digital worlds around emotional needs (Proposition 4. Emotional needs)}

Fulfilling basic emotional needs will always remain the central basis for creating positive experiences with technology.

Comment: We would like to address that from the perspective of today humans will not much change with respect to their brain architecture in the next hundreds of years (although with the development of the gene scissor CRISPR/CAS 9 we cannot be ultimately sure). Considering the lengthy process of evolutionary development, humans very likely will possess the same needs in hundreds of years as today. These psychological needs arise from primal emotional systems, which have been carved out in much detail by Jaak Panksepp [100] using both deep brain stimulation and pharmacological challenges of the mammalian brain. His work resulted in the primal emotions of SEEKING, LUST, CARE, PLAY and FEAR, RAGE, SADNESS; the capital letters indicate that this are primal emotions which should not be mixed with other forms of emotions. Here, recent work demonstrated that emotional urges arising from these in-built tools for survival relate to different facets of online usage/addictive tendencies. These primal (emotional) needs represent a building block around which digital-technological worlds need to be designed in order to provide humans with a health-promoting environment in line with our evolutionary heritage. 


\section{A.4.5. Digital Depression and digital etiquette (Proposition 5. Digital Depression)}

The continuous presence of technology threats happiness, well-being, and social norms.

Comment: Technology pervades all aspects of our lives, and exerts continuous impact on thinking, feeling and social interaction. In contrast to impairments of cognitive abilities ("digital dementia"), the term "Digital Depression" [101] underlines threats to subjective well-being and happiness, and the unintended side effects of social media, fitness trackers, and continuous smartphone use. For example, smartphone mediated behavior often break up established social norms, e.g., full attention for the conversation partner versus parallel smartphone use [102]; fixed appointments versus last minute cancelling/delay of a date via WhatsApp. It therefore needs a conscious reflection on a digital etiquette, i.e., the integration of technology in established culture, the adequate use of technology in social settings or intentionally technology-free areas. This aspect not only refers to peoples' private lives and wellbeing, but also is highly relevant for the working domain, where digital etiquette becomes part of the business culture design.

Appendix A.5. Propositions on "Genetics": Lude Franke

\section{A.5.1. DNA-based discrimination (Proposition 1)}

With a DNA profile that is costing only $€ 30$ (2017 price) it will become possible to predict who is at high risk for developing disease and what kind of lifestyle changes might help to prevent to get these diseases.

Prices of genetic assays have fallen in the last decade tremendously. The cost is now only $€ 30$ to generate a DNA profile, and with ever increasing knowledge how to predict disease based on this DNA information, it is now becoming possible to infer who is going to get a certain disease and who is not.

However, this is also presenting important ethical, legal and societal implications: To what extent do individuals want to know that they are at increased risk for developing Alzheimer's disease or cancer? And it is likely that drug development will keep up a similar pace, such that if you know that you have this high risk of cancer, and thus should seek have regular medical check-ups to detect cancer at a very early stage, also feel confident that should such a disease emerge, you have a very high chance of getting cured?

Certain countries (e.g., the Netherlands) currently have laws in force that allow insurance companies to ask clients whether DNA testing has been conducted and if so, what the outcomes have been in order to set an insurance fee. Will this lead to individuals who will have to pay excessive insurance fees because of their genetic make-up? And will law enforcement agencies be allowed to request such DNA information in order to solve criminal acts?

\section{A.5.2. DNA-based pharmaceutics production (Proposition 2)}

Developments in genetics will enable generation of a tremendous amount of insight in the pathology of disease, which will help pharmaceutical companies to decrease drug-development costs.

The cost of drug development is increasing rapidly. While the cost of the development of a new drug was $\$ 1$ billion 10 years ago, it is now over $\$ 2$ billion. One major reason why costs have increased is that drug companies often do not know which particular biological process, gene or protein to target, because it is unclear what the 'key driver' of disease is. Consequently, pharmaceutical companies typically rely upon costly screening facilities that systematically test hundreds of thousands of different chemical compounds for potential therapeutic effects. Strategies that could help these companies to 
better choose what specific compounds to test, would potentially save costs and time to bring drugs to market.

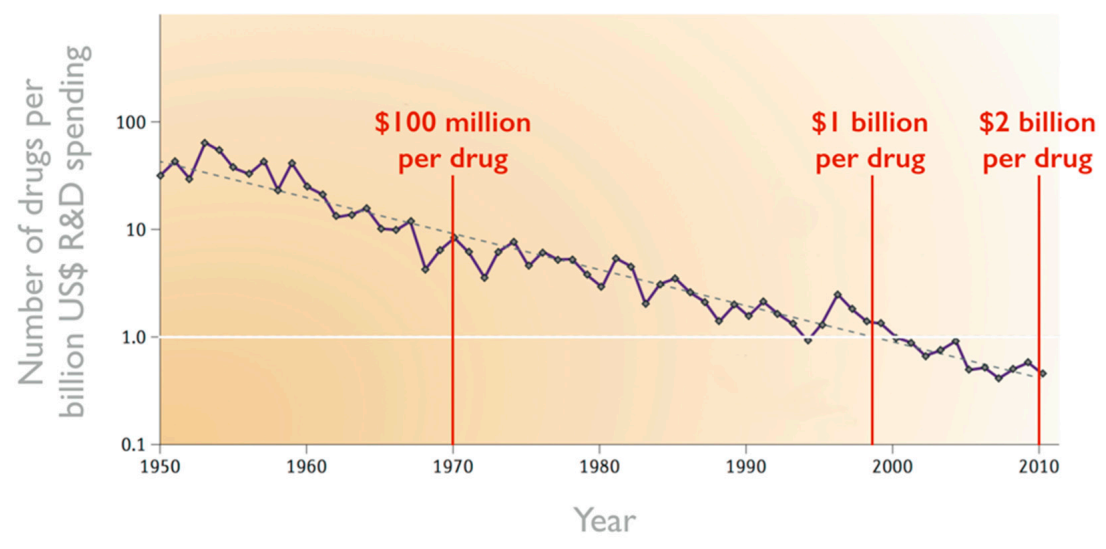

Figure A1. Problem of current drug discovery (adapted from Scannell et al., Nature Reviews Drug Discovery 2012).

Paradoxically, the study of healthy individuals can help to improve drug discovery substantially, by using genetic information in conjunction with effects on genes, metabolites and proteins: Since 2006 over 10,000 genetic risk factors have been identified. Some of these increase type 1 diabetes risk, others increase the risk for cancer, while others increase cholesterol levels. Having one or two genetic risk factors, for instance for type 1 diabetes, will not be sufficient to cause this disease. You need to carry many of these risk factors in order to get sick. This means there are many healthy individuals that have a few risk factors for type 1 diabetes. As such, when investigating healthy individuals for these 10,000 genetic risk factors it becomes clear that for each of these risk factors, healthy individuals can differ in their 'genotypes' (some having the risk-increasing alleles, some having the risk-decreasing alleles). This means that individuals differ slightly in their risk for developing certain diseases.

It is this subtle difference that we can exploit: by knowing who is at slightly increased and who is at slightly decreased risk for a certain disease and by also having measured the activity of genes, metabolites and proteins it is possible to ascertain whether this genetic risk is having an effect on them. By doing this systematically it will become possible to identify the specific biological processes that are disrupted in disease, which will provide pharmaceutical companies with important information where to concentrate their efforts on. Given the fact that data generation costs have fallen sharply, computational capacity has grown explosively and new machine learning techniques are now becoming available we expect that data drive drug discovery will enable the pharmaceutical industry to increase its efficiency to develop new drugs while improving the efficacy of these drugs.

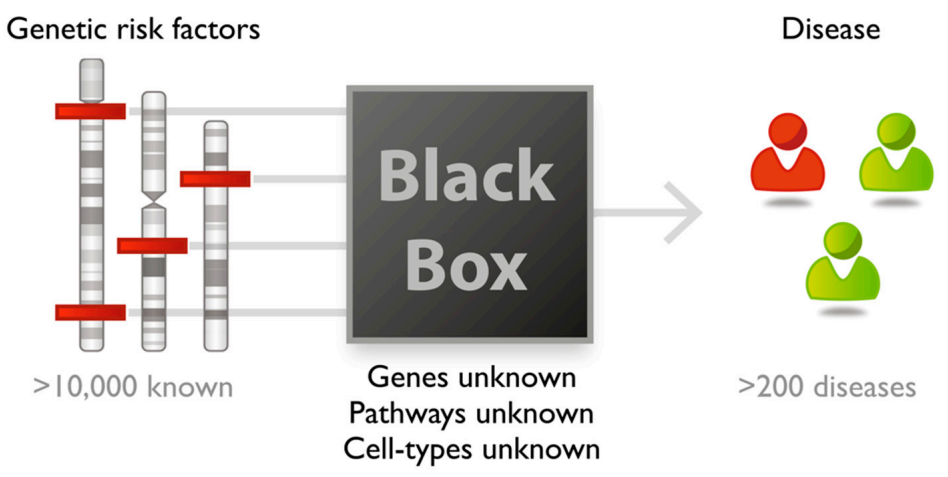

Figure A2. The mechanisms leading from genetic risk factors to diagnosable disease currently constitute the 'black box' of missing knowledge. 


\section{A.5.3. DNA-based disease curing (Proposition 3)}

It will become technically possible to cure rare, genetic diseases by changing DNA.

The CRISPR-CAS9 technique now makes it possible to very specifically change DNA. In theory this also will make it possible to cure rare, genetic diseases, by changing the DNA of embryos. While this might be a very sensible strategy to consider for couples who both are carriers of a very severe mutations (and thus having very high chances of getting a child that will get critically ill), setting this in motion will show a very slippery slope: what diseases to consider, and also where to stop? These are important things to think about right now, given the tremendous pace at which these technological developments have progressed in the last few years.

\section{Appendix A.6. Propositions on "Big Data Analytics": Peter Parycek and Gabriela Viela Perreira}

\section{A.6.1. Transformation of governance models (Proposition 1. Digital policymaking)}

Digital transformation is changing the process of policymaking and altering governance models in a disruptive way. The pervasiveness of the data concept in these workflows when combined with artificial intelligence and automated decision-making process, as well as the growing number of well-organized digital heterogeneous communities, has significant implications for the transformation of governance structures.

Comment: There are implications for data analytics and automated decision-making in governance, such as the value conflicts over the ends and means of data, which require ethical algorithms and informed decision-making by stakeholders. An interesting aspect pertains to the impact of digital transformation in government. The pervasiveness of big data analytics is transforming governance into a rational process in a self-organized digital environment. The actors and the players are not fixed but are continuously evolving and moving from the different disciplines. Consequently, governance models will be organized in a dynamic way. The roles, actors and data owners are not clearly defined. Yet, the process for defining clear problem-oriented solutions that target the needs of citizens and guarantee of cohesive societies is clearly described.

\section{A.6.2. Governance knowledge gap (Proposition 2. Global digital risk management)}

Different scenarios of global governance show that dealing with uncertainty, the uncontrolled creation of systematic risks, a lack of public accountability, and lack of knowledge about how to operate in global systems endanger the effective delivery of comprehensive solutions for societal problems. Issues surrounding personal data protection and privacy are also impacted, stemming from the misinterpretation of demands and a lack of context-specific solutions.

Comment: Information sharing and cooperation, together with participatory practices in policymaking, are key elements in discussions surrounding the use of ICT to enable collaborative governance [103]. There is a need to reconstruct governance and democracy into hybrid forms of organized cooperation that go beyond national government [104]. Effective collaborative governance requires the generation of value by applying collective intelligence for innovative solutions to societal problems. Building the necessary competences, and bridging the information and knowledge gap among stakeholders, involves the development of strong accountability and transparency in an environment of trust. 


\section{A.6.3. Resilience strategy for new governance models (Proposition 3. Resilient governance)}

The application of emerging technologies to governance implies new ethical issues, together with environmental, privacy and equality aspects. To effectively tackle these concerns, legal solutions need to be sought for anticipated problems.

Comment: The digital transformation of public services should be developed in a responsible manner, one that comprehensively addresses the social and ethical dimensions of change. To achieve this, Stahl [105] recommends that a regulatory framework and adequate infrastructure for the development of social/societal responsibility be provided. In the context of smart governance, we raise two main issues suggested by the author in support of this requirement: (1) the need to address the wide range of current and new ethical issues arising from ICT, modelled along the lines of environmental, privacy or equality impact assessments; and (2) the need to proactively consider legal solutions to resolve those problems that might arise from the application of future and emerging technologies to public administration. Further, and following Markus and Mentze [106], in order to minimize the negative consequences of new governance models and to create a resilience strategy, future-oriented methods of sociotechnical analysis are required. These may be built into the techniques used by policy makers to develop policies and public services. This approach may also be deployed to design related governance arrangements; including "non-functional" requirements such as security, privacy, safety, quality of life, and contained systemic risk.

\section{A.6.4. Intelligent digital ecosystems combining data and people (Proposition 4. Cybersocial systems)}

The combination of data resources and human resources is the foundation for smarter decisions and evaluation at all stages of the policy cycle. There is a need to change the relationship between humans and algorithms that leads to a socio-material practice of automated decision-making. This requires a high level of trustworthiness of data sources to avoid unreasoned decisions.

Comments: The use of data-driven decisions in policymaking implies modifications in the relationships between humans and algorithms within the framework of knowledge-based activities. These changes can lead to automated decision-making. They may also have consequences for those outcomes of the policymaking process that are data-driven. Examples include the questioning of the extent that sources are reliable, privacy issues and the digital divide. The possibility that the use of ICT will have negative consequences can never be completely predicted or eliminated. Potential risks, however, can often be mitigated through careful sociotechnical analysis in advance of system building [106]. In order to avoid unwanted/unreasoned decisions based on imbalanced, biased or erroneous algorithm-people interactions, Artificial Intelligence literacy has to be developed amongst human decision makers. This would facilitate the prevention and identification of possible mistakes, and aid in the development of techniques for guaranteeing the trustworthiness of data providers.

Appendix A.7. Draft Propositions for "Cybersecurity and Warfare": Richard Hill

\section{A.7.1. Definition of War (Proposition 1)}

The nature of war is changing and acts that are not at present considered to be "war" may become the primary means by which war is waged in the future.

Comment: There are differing definitions of the term "cyber warfare" (this section is largely taken from [107]). Strictly speaking, it refers to massive state-organized assaults, akin to conventional warfare, but it is also used more generally. Indeed, the term "war" is often used figuratively, as in economic war [108], the war on drugs, and the war on terrorism. A recent academic work uses "cyber 
war" figuratively to refer to utilization of digital networks for geopolitical purposes, including covert attacks against another state's electronic systems, but also the variety of ways the Internet is used to further a state's economic and military agendas [109].

As Clausewitz said, war is the continuation of politics by other means. The "other means" are the use of force. Such force has traditionally been used to kill, imprison, or enslave a more-or-less large number of people, and/or to destroy buildings, factories and infrastructure-sometimes only military but at times also civilian.

But alternative types of force are emerging: cyber-attacks can degrade infrastructure, and even military capabilities, to the point that an adversary is forced to yield.

\section{A.7.2. Cyberwar Prevalence (Proposition 2. Cyberwar)}

Cyber-war may replace mass killings and bombing as the preferred way of forcing an adversary to submit.

Comment: It is increasingly apparent that the security of IoT devices is inadequate [110] and that that could have catastrophic consequences [111,112]. Further, unlike physical weapons, cyber-weapons can be replicated at essentially no cost.

The WannaCry [113] incident can be considered a harbinger of things to come: a state-sponsored cyber-attack on the infrastructure of another country (e.g., from the electrical power grid, the airline control system, government computer systems, etc.). Such an attack could paralyze a state in the same way that intensive aerial bombardment can paralyze it.

With the increasing importance of ICTs, and the increasing dependency of everything on ICTs, we may reach a stage where force can be used effectively to destroy ICTs systems, thus achieving the desired goal of forcing an adversary to surrender without having to kill people directly or to bomb facilities.

This is very different from the current use of ICTs in warfare.

\section{A.7.3. Geneva Digital Convention (Proposition 3. Digital-war convention)}

There is a need for a treaty under which states agree, inter alia, not to attack civilian digital infrastructure in times of peace, not to acquire or stockpile malware, and immediately to inform concerned manufacturers when they become aware of vulnerabilities in software or hardware.

Comment: In March 2017, Wikileaks published information on use by the US Central Intelligence Agency (CIA) of various hacking tools and malware [114]. Apparently, the CIA has lost control of its arsenal of hacking tools, which are now available to entities other than the CIA, including presumably cyber-criminals. Attacks using these tools cannot be traced back to the source of the attack.

In mid-May 2017, the WannaCry [113] attack prompted Microsoft to renew the call it had made a few months earlier for a "Geneva Digital Convention" [115].

Microsoft has made three specific proposals [115]:

- Clauses for a binding treaty

- An agreement between high-tech companies

- The creation of an organization that would seek to attribute cyber-attacks, that is, to determine who initiated the cyber-attack

I would go further than what Microsoft has proposed regarding treaty clauses.

\section{A.7.4. Mass Surveillance (Proposition 4)}

Surveillance of citizens other than on the individual order of a judge violates human rights, is not effective, and is a form of cyber-attack. 
Comment: It is well-known that many states, including states that consider themselves to be democratic, have implemented mass surveillance. By "mass surveillance" I mean any form of surveillance and/or eavesdropping that is not necessary and proportionate and authorized by the national courts of the target of the surveillance.

The stated goal of such surveillance is to combat what the states in question consider to be terrorism.

But such surveillance is not and cannot be effective in countering individual acts of violence: could it prevent bank robberies?

In my view, mass surveillance violates the human right to privacy and it is form of cyber-attack.

\section{A.7.5. Lethal Autonomous Weapons Systems (Proposition 5. AI warbots)}

Lethal Autonomous Weapons Systems have limited potential, because either they are constrained in scope, or they can be deactivated on command.

Comment: A Lethal Autonomous Weapon System (LAWS) can be defined as a system designed to select and attack military targets (people, installations) without intervention by a human operator.

For example "ground-force" LAWS could attempt to destroy a specific type of target in a specified volume unless it is specifically instructed to cease.

We underline the key point: to what extent is the system autonomous [116]? If it is fully autonomous, then it is far too dangerous to be deployed, because there is no guarantee that it will not attack friendly forces (either because it fails to distinguish them from adversary forces, or because it malfunctions).

But if the LAWS can be instructed to cease operation, what guarantee is there that the adversary will not be able to send such instructions? Or, worse, change the programming of the LAWS so that it attacks the party that originally deployed the LAWS?

In addition to the above practical issues, and governance issues, there are of course ethical issues associated with LAWS [117].

Appendix A.8. Propositions on "Ethics and the Digital:" Claude Kirchner E Gilles Dowek (INRIA, Le Chesnay, France)

\section{A.8.1. Ethics, Digital, and Law (Proposition 1. Pervasive computation ethics)}

In the developing digital world, create instruments to stimulate and organize the useful and necessary complementarities and synergies between ethics and law.

Comments: The complementarities between ethics and law are both fundamental and non-trivial to organize. One should create, for instance at the European level or at the nations levels ethical committees in charge of the general thinking about ethics in the digital world including ethics of usages, ethics of conception, general ethics impacted by the digital. These committees should interact with the legislator to allow for the ethical thinking to sow laws in the appropriate way. A typical example concerns personal data. Conversely, the legislator should be able to seize ethical committees.

\section{A.8.2. Ethics, Digital, and Science (Proposition 2)}

Organize the appropriation and development by scientists of the ethical reflection about the general development of sciences as well as the operational ethical questions posed by scientific experimentations and developments.

Comments: The digital revolution, issued from sciences and technologies, deeply impacts the scientific method itself with strong consequences in all fields of science. Typically in France, 
a national committee (http:/ / cerna-ethics-allistene.org) has been set-up to conducts a conceptual and methodological reflection on the ethics of scientific research in Digital Science and Technology [118]. IRB or operational ethics committees have been created in universities (e.g., http:/ / www.univ-toulouse. $\mathrm{fr} /$ recherche-doctorat/recherche/comite-d-ethique) or research institutes (e.g., https:/ / www.inria.fr/ en/institute/organisation/committees/coerle).

Note: Moreover, UNESCO'S initiative to revise its main texts and recommendations concerning scientific research, scientists and ethics: the 1974 "Recommendation concerning the status of scientific researchers" (http://portal.unesco.org/en/ev.php-URL_ID=13131\&URL_DO=DO_TOPIC\&URL_ SECTION=201.html) and the 1999 "Declaration on science and the use of scientific knowledge" (http://www.unesco.org/science/wcs $八 T 1 \backslash$ textquotedblrighteng/declaration_e.htm).

\section{A.8.3. Ethics, Digital, and Innovation (Proposition 3)}

Consider ethics as a competitive argument for industry 4.0 .

Comments: Algorithms, formal mechanization, machine learning, automation and robotization transform industry and economy. In the context, ethics shall become a differentiating argument that empowers consumers and users. Typically how shall we allow a user to choose a search engine that takes ethical and independently certified engagements about the treatment of personal data? How shall we enlighten the choice of a product build in a fully automated factory, with its consequences on efficiency, human labor and the human role in the society?

\section{A.8.4. Ethics, Digital, and Cybersecurity (Proposition 4. Cybersecurity ethics)}

Ethical hacking and high security informatics labs should be developed and organised in frameworks allowing cybersecurity certification as well as ethical assessments.

Comments: Cybersecurity is a universal, perpetual and crucial concern of the digital society. Like in biology where high security labs (labeled P1-P4) have been created and monitored, high-cybersecurity labs should be developed in the academic world and not only in the military, police or governmental information labs. These academic labs should be developed under a strict academic control to allow for ethical hacking and the ethical development of concepts and tools to understand and master malwares and cybersecurity threats.

\section{A.8.5. Impact of the digital world on ethics: towards formal ethics (Propositon 5. Formal Ethics)}

Develop the study of ethics itself in the deeply renewed context of the digital world, by providing concepts, models and tools to formalize and study ethics and its foundational corpuses.

Comments: Humanities are profoundly impacted by the digital revolution. Ethics do not escape this and we now need to understand how could we use the digital concepts and tools to model the idea of ethical values or the notion of dilemmas or of conflict. In addition for humans to better understand ethics and its developments, this will in particular allow us to better understand how we can learn machines to get ethical behaviors and possibly to develop ethical reasonings. 
Appendix A.9. Propositions on "Global Social Change": Dirk Helbing und Stefan Klauser

\section{A.9.1. Digital Upgrade of Democracy (Proposition 1. Deliberated democracy)}

Digital technology allows for the design of a new form of democracy with transparent, uncensored, fair and moderated discourses, in which $\mathrm{AI}$ is used to support the constructive exchange of ideas and the identification of different perspectives that need to be integrated. Responsible behavior and high-quality contributions would be promoted.

Comment: More and more people claim that digital democracy is the evil that makes our world ungovernable [119]. Modern mass media and social media tend to create 'filter bubbles', which are reinforcing opinions, while reducing the ability to handle different points of view. Digital information becomes increasingly personalized, manipulative, and deceptive.

But instead of trying to revive governance principles of the past, which have failed to embrace the complexity and diversity of modern societies, we should engage in digitally upgrading democracy through the use of Massive Open Online Deliberation Platforms (MOODs) [120]. Letting people decide about "yes" or "no" is not enough. Citizens should be able to continuously engage in online deliberation processes, where they can feed in their ideas and voice their preferences on different aspects of a topic. A refined, more inclusive process would enable people to learn about and to unfold the different aspects of a complex political topic.

\section{A.9.2. Finance 4.0+ (Proposition 2)}

In order to solve the challenges of the 21st century, the financial system has to be altered into a multi-currency system representing different positive and negative externalities and incentivizing behavior that is aligned with our societal goals and values.

Comment: Computer simulations about the world's future predict severe resource shortages-and linked to this-an economic collapse. This is known at least since "The Limits to Growth" study commissioned by the Club of Rome, and the "Global 2000" study issued by the US government. The UN Sustainability Agenda 2030 is giving the world less than 15 years of time to solve this problem.

It is necessary to create a multi-dimensional incentive and reward system beyond money. We call this system finance $4.0+$. This can now be built by combining the Internet of Things, blockchain technology and complexity science. To boost a circular economy, we need a system that can measure, value and trade positive and negative externalities - external effects of interactions between people, companies and the environment. Desired values can be agreed on in a participatory, subsidiary way, as suggested in Proposition 2.

\section{A.9.3. Democratic Capitalism (Proposition 3)}

The digital technology has the potential to reinvent the money system such that it empowers people to be innovative and to engage in social and environmental projects. Moving beyond venture capitalism towards crowd funding for all would enable participatory budgeting and democratic capitalism.

Comment: One cannot put the interests of a few hundred people over the well-being of society as a whole. As long as the mechanisms of the monetary and financial system don't benefit everyone, the world will not be stable and sustainable on the long run. Fortunately, there are alternatives. The failed approach of pumping trillions into the economy from the top by means of "quantitative easing" could be replaced by a new approach, where the money is created from the bottom. The idea is [121] that everyone would regularly get an "investment premium", which would have to be 
distributed to people, companies or institutions with good ideas, or those who are engaged in social or environmental projects. Then money and resources would flow into the activities we find most important. This would boost innovation in a pluralistic manner. Such an approach would combine our two most successful organizing principles-democracy and capitalism-in a new way, and replace today's market-driven democracy, where capitalism threatens to destroy democracy.

\section{A.9.4. City Olympics (Proposition 4)}

Competitions for the best kinds of technologies, solutions for resource shortages, and a quick implementation of new solutions can be achieved through Global City Olympics.

Comment: Cities and social communities can be important agents of global change. A combination of competition and collaboration among cities can advance us in our efforts to solve the challenges of the 21st century. Thus, we follow Elinor Ostrom and suggest a "polycentric" approach to solving global problems [122]. The idea of "City Olympics" [123] may become a powerful tool. City Olympics would have a sportive spirit. Cities all over the world would engage in friendly competitions to achieve the best scientific and technological progress, as well as mobilize collective action to counter climate change. They would reach the highest possible degree of citizen engagement. After the competitive phase of each Climate Olympics, there would be a cooperative phase, where the best ideas, technologies and urban governance concepts would be exchanged among the participating cities.

\section{Appendix A.10. Propositions on "Sustainable Development": Armin Grunwald and Ortwin Renn}

\section{A.10.1. Digital efficiency rebounds (Proposition 1. Efficiency rebounds)}

The increase of efficiency by digital technology is linked to rebound effects regarding material use and natural resources use. These rebounds should become subject of research and political efforts.

Comment: There is no automatism towards realizing more sustainability by expanding digitization. While in the previous wave of digitization (late 1990s, expectations of an emerging "New Economy") big hopes addressed a de-materialization or immaterialization of economic processes with much lower consumption of natural resources, reality has shown that these promises were only partially met [124]. Academic studies demonstrated that the potential for energy conservation and material reduction were less pronounced due to high energy consumption of digital facilities themselves, automation of conventional industrial processes without major technical innovations in manufacturing itself and short live spans of many electronic devices. Most important, however, has been the rebound effect by which more efficiency also increased consumption and waste production. Bringing together digitization and requirements of sustainability will need dedicated research and political effort. Most notably, digital strategies need to be designed in a way that sustainable practices and principles are not treated as byproducts but as parallel objectives [125].

\section{A.10.2. Digital Threats Related to Democracy (Proposition 2. Digital democracy)}

Digital services have the potential to enhance procedures of direct democracy but they also threaten basic human rights such as privacy, personal freedom and sovereignty.

Comment: While IT technologies have often been seen as strong supporters of further democratization for decades now (cp. e.g., the high expectations towards the Internet in its early stage) it becomes more and more obvious that digitization will lead (or: already led) to severe challenges to democracy (loss of privacy, omnipresent surveillance, Big Data, socio-bots etc.) [126,127]. It is in 
particular discomforting that political blogs are fed by intelligent software programs that scan all entries and provide opinionated responses giving the impression that the opinions raised in these blogs are shared by millions of people. Some observers credit this automatic response machine for the surprising success of the Trump presidency. Because sustainable development involves (following the Rio documents) democratic ideals such as participation, open discourse and access these new developments of manipulating the open public discourse and nudging strategies must be carefully observed and analyzed. This is first of all an issue for regulation and political participation in an internet era, but is also a more fundamental issue of authorship and identity that need to be addressed [128]. Beyond monitoring and regulation, there is the need to explore the possibilities and opportunities for e-democracy but also to understand the barriers and constraints.

\section{A.10.3. Loss of and redefining Labor (Proposition 3. Redefining labor)}

Digital services have the potential to serve the sustainable development goals (SDGs) particularly in many low-income countries. However, it is crucial that local actors are in control of this modernization effort.

Comment: Further digitization has high potentials not only to help the industrialized countries to keep or extend their welfare but also to support development in developing countries [129]. However, those potentials will not be effective by themselves but rather need dedicated scientific and political effort. Strategies are needed that assist people in particular remote areas with rural infrastructure to make use of digital services for business, education and social communication.

\section{A.10.4. Transdisciplinary, transformative and transition management (Proposition 4. Transdisciplinarity)}

Digital services are a key example for the need of interdisciplinary and transdisciplinary research programs. It is important to include the technical, economic, social and psychological impacts in technology assessment and to strive for an integrated knowledge application and governance including major stakeholders and the affected public.

Comment: All these research activities may not start from scratch. The many approaches and experiences in transdisciplinary research, transformative science, transition management, technology assessment, sustainability science etc. provide theoretical and empirical foundation on which further dedicated studies can build. The methodological instruments as well as the transdisciplinary approaches are readily available to shape the future landscape of researching the relations between digitization and sustainability [125]. What is needed now is the political will and the respective funds to do so.

\section{Appendix B. Methodology, Propositions on the Future Perspectives on Digital Transition of the Japanese Expert Round Table on Sustainable Digital Environments}

\section{Appendix B.1. Conclusions of the Japanese 2017 ERT}

Six Japanese scientists and the first author of the present paper participated in the Japanese ERT. Before the workshop, all participants were provided with Goals 1-3 listed above and a comprehensive workbook including a definition of main concepts (such as sustainability, digital environment, transdisciplinarity). In this way, the ERT was able to focus on key messages provided by the participants. These were collected after the Japanese ERT as a proposition on unseens involved in the digital transition (see the appendix in Sugiyama et al. [31]; a summary table is presented in Appendix B).

According to the Japanese ERT, the main technology innovations include the following:

- The automatization of service, production, and transportation processes 
- The management of Big Data

- Artificial intelligence in all domains of society

- Conversational AI that humanizes robots and human-machine interaction

- Digital biotechnology and biocomputers

- This digitalization shows essentially new properties, in particular:

- Globalized networking

- The ubiquity of digital technologies in all domains of life on local and global scales.

The discussion also coined the term digital vaulting, denoting that the human-environment relationship has become engulfed by digital media and thus by genuine indirectness (see Figure 1).

We should note that the inclusion of biotechnology, in particular DNA as a genuine digital conception based on quaternary number-based conception (established by two pairs of directed acids) [4] was new for some participants of the Japanese ERT. We mention two issue briefly which may illustrate unseens of the digital transition on the science system itself by two examples from biology, i.e., first, a reductive conception of evolution and second, the understanding of biocomputers. The digital theory of molecular genetics paved the way for a successful, consistent understanding of the molecular mechanisms involved in evolution. This is, without doubt, one of the greatest success stories of science and allowed for the development of a theory and engineering of genetic modification. But as a consequence (unseen), evolution has been conceived exclusively as a random genetic drift that (by chemicals and radiation) [130]. Leading ecologists such as E. O. Wilson criticized this overly restricted and sometimes dogmatic view [131] which includes a narrow, semantic-free concept of information [132]. The ignoring of other factors of evolution such as the role of superorganisms (e.g., the socially mediated learning of groups [133-135]) or epigenetic (non-genetic) heritage effects $[133,136]$ may be seen as an unseen. With respect to biocomputers, the invention of biocomputers which include genetical modified E. coli bacteria may induce an unseen as cells are cognitive systems (whose behavior may fundamentally differ from those of transistors) may open new floors and unseens $[13,137]$ and ask for a special understanding of (kinds of macro-bionic) computers.

\section{Appendix B.2. Specific Unseens Identified by the Japanese ERT}

One of the main messages (I) of the Japanese ERT was that "cultural context matters" (all quotes in this paragraph are from Sugiyama et al. [31]). Even among experts, "religious views have an effect", e.g., on preferences for humanoid computers. Whereas for Christians, resurrection and salvation make the "embodiment" irrelevant," "sacralization of the natural world and human technology in Shinto and the positive spin given to human life in Shinto and Buddhism promote the development of robotic engineering and the glorification of the humanoid robot in Japan." [138]. Another issue may be linked to "public engagement—communication, consultation, and participation," which also refers to "transdisciplinary discussion in unwanted societal changes as well as a shift in science from analog to digital modeling and structure." Obviously, following a meritocratic system for deliberations, the roles and decisions of virtuous and capable leaders play a much larger role than in Western societies $[137,139,140]$. Thus, the role of academia in (transdisciplinary) practice-science dialogues in Japan may be more important than in Western countries. Nevertheless, "recent reports published in Japan on AI and society indicates that there is a desire among experts to co-inhabit with AI and robots." Although, as mentioned, transdisciplinary processes may be differently shaped in Japan than in other places such as Central Europe, the need for societal dialogues has been stressed by various ERT participants. Simplified, we may learn from this that there are several modes of coping with digitalization, for instance a Western-US-European-mode and a Japanese mode. Ariza Ema presented two unseens that are most presumably related to the cultural dimension. One is the exclusion of the "want-nots," i.e., those who do not want digital technologies from social core processes. The other is a version with strong Western-US bias. 
Table A1 presents 13 unseens identified in the 22 propositions provided by the seven ERT participants. Three are linked to economic changes on the level of a national or global level. The Japanese experts, in particular Degeuchi, identified platform owners as winners through new B2C relationships who were afraid of possible platform lock-in (see B.1.1 Appendix B). There were concerns that the digitalization of business and industry in many respects, including the downgrading of education, status, income, and security of low-capability workers, much resembles the fate of day laborers (B.1.2). Third, the disputed fear of AI-induced unemployment [141] has been mentioned.

Another cluster of unseens refers to a change in social structures, and these culminate in the proposition that digital transformation calls for redefining humanity (B.4.1) as new forms of relationships among humans but also new forms of human-(smart)machine interactions. These call for new forms of emotion, faith, and personality. Linked to this is Mori's concern on a (monopolistically owned) networked superintelligence (B.4.2) that may abandon decentralized, democratic multi-knowledge systems.

Much attention has been given to the classification of new risks that emerge for humankind. In principle, there are two new types. We may identify new systems (e.g., interconnected systems of global scale) digital systems may cause new-unknown risks (B.3.2 and B.6.1). Shiroyama's concern is for endogenous black-swan-like threats in financial and military systems, whereas Kishimoto focuses on the digital divide and personal risks. And finally, new risks and unseens for human- and ecosystem-development-related biotechnological interventions have already been stressed by Scholz as major challenges for humankind [4]. Here, the above mentioned genetic modifications directed evolution that may follow human desires but not ecological resilience may become an unseen.

The below Table A1 comprises the labels (short description), the primary systems involved, the specific (digital) technology innovation and the originally intended changes by the technology innovation, and the main properties of the unseens. 
Table A1. Labels of unseens, system of rebounds, technology innovation, intended change and description of unintended side effects (for a detailed description see Appendix B in [31]).

\begin{tabular}{|c|c|c|c|c|c|}
\hline Scientist & $\begin{array}{c}\text { Label of Unseens (Numbers } \\
\text { See [31]) }\end{array}$ & $\begin{array}{l}\text { (Primary) System of } \\
\text { Unsseens }\end{array}$ & Technology Innovation & Intended Change & Properties of Unseens \\
\hline \multirow{3}{*}{ Hiroshi Degeuchi } & $\begin{array}{l}\text { Platform Lock-in on the B2C } \\
\text { market (B.1.1) }\end{array}$ & Economics (trade) & Platforms & $\begin{array}{l}\text { Better, direct } \mathrm{B} 2 \mathrm{C} \text { relations (in } \\
\text { economic system) }\end{array}$ & $\begin{array}{l}\text { Platform providers build } \\
\text { business oligopoly }\end{array}$ \\
\hline & $\begin{array}{l}\text { Low-capabilities franchise } \\
\text { workers (B.1.2) }\end{array}$ & Economics (labor market) & Global web job market & $\begin{array}{l}\text { Freelancers may operate and work in a } \\
\text { flexible manner in the market }\end{array}$ & $\begin{array}{l}\text { Downgrading of income, social security, } \\
\text { and professional education by } \\
\text { franchise-laborers }\end{array}$ \\
\hline & Reality shift (B.1.4) & $\begin{array}{l}\text { Ontogenetic development: } \\
\text { Experiential, personal } \\
\text { knowledge, individual, } \\
\text { groups, countries }\end{array}$ & $\begin{array}{l}\text { Oligopoly-based, ubiquitous, } \\
\text { digital, worldwide, economically } \\
\text { driven web platforms }\end{array}$ & $\begin{array}{l}\text { Personalized information of } \\
\text { maximal interest }\end{array}$ & $\begin{array}{l}\text { Different individuals get by biased, } \\
\text { disembedded, (artificially) constructed } \\
\text { reality information without } \\
\text { "evolutionary feedback loops" }\end{array}$ \\
\hline \multirow{2}{*}{ Arisa Ema } & Ignoring "wants-not" (B.2.1) & $\begin{array}{l}\text { Everyday } \\
\text { world; individual }\end{array}$ & Global net and social networks & Convenient, economic, public service & $\begin{array}{l}\text { Disadvantaging the "have-nots" and the } \\
\text { "want nots" }\end{array}$ \\
\hline & $\begin{array}{l}\text { US-/Western-dominated } \\
\text { culture (B.2.2) }\end{array}$ & $\begin{array}{l}\text { Everyday world; } \\
\text { human species }\end{array}$ & $\begin{array}{l}\text { Algorithmic, AI-shaped } \\
\text { data processing }\end{array}$ & Including all & US-/Western-imperialism \\
\hline Atsuo Kishimoto & $\begin{array}{l}\text { A new digital risk } \\
\text { society (B.3.2) }\end{array}$ & $\begin{array}{l}\text { Societal risks; global, } \\
\text { human species }\end{array}$ & Global web & Improving the world (human evolution) & $\begin{array}{l}\text { New personal risks such as protection of } \\
\text { privacy, freedom of choice, right to know, } \\
\text { reduction of disparity }\end{array}$ \\
\hline \multirow[b]{2}{*}{ Junichori Mori } & Redefining humanity (B.4.1) & $\begin{array}{l}\text { Social system, human } \\
\text { species }\end{array}$ & $\begin{array}{l}\text { AI, cyborgs, IoT, new forms of } \\
\text { man-machine interactions }\end{array}$ & Improving the world (human evolution) & $\begin{array}{l}\text { New forms of emotions, faith, } \\
\text { or behavior }\end{array}$ \\
\hline & $\begin{array}{l}\text { One superintelligence } \\
\text { emperor (B.4.2) }\end{array}$ & $\begin{array}{l}\text { Diversified, decentralized, } \\
\text { global (democratic) } \\
\text { system, human species }\end{array}$ & AI on globally networked big data & Improving the world (human evolution) & Loss of a diversified, democratic society \\
\hline \multirow[b]{2}{*}{ Roland W. Scholz } & $\begin{array}{l}\text { Biotechnological-governance } \\
\text { (including } \\
\text { biocomputers) (B.5.1) }\end{array}$ & $\begin{array}{l}\text { Cellular and genetic } \\
\text { systems; cell }\end{array}$ & $\begin{array}{l}\text { Digitalization of evolution and life } \\
\text { (DNA), monitoring and } \\
\text { engineering cell processes on } \\
\text { the nano-level }\end{array}$ & $\begin{array}{l}\text { Human health, more biomass, smart and } \\
\text { efficient computers }\end{array}$ & $\begin{array}{l}\text { Loss of evolutionary resilience; } \\
\text { computers as decision makers }\end{array}$ \\
\hline & $\begin{array}{l}\text { Mental internet } \\
\text { disorder (B.5.2) }\end{array}$ & $\begin{array}{l}\text { Molecular } \\
\text { neuropsychology and } \\
\text { epigenetics; cell, } \\
\text { organ, individual }\end{array}$ & $\begin{array}{l}\text { Virtual worlds (e.g., 3D } \\
\text { gaming worlds) }\end{array}$ & $\begin{array}{l}\text { Information, stimulation, joy, } \\
\text { entertainment, }\end{array}$ & $\begin{array}{l}\text { Cyberaddiction (e.g., internet } \\
\text { pornography addiction), internet gaming } \\
\text { disorders }[97,142,143]\end{array}$ \\
\hline Hireaki Shiroyama & $\begin{array}{l}\text { Black Swan security } \\
\text { management (B.6.1) }\end{array}$ & $\begin{array}{l}\text { Finance, military, ect., } \\
\text { society, global species }\end{array}$ & $\begin{array}{l}\text { Genuine, ubiquituous, } \\
\text { interconnectedness }\end{array}$ & Global action & New systems of digital systems risks \\
\hline \multirow{2}{*}{ Masahiro Sugiyama } & $\begin{array}{l}\text { AI-induced } \\
\text { underemployment (B.7.1) }\end{array}$ & Job market & $\begin{array}{l}\text { Facilitating uninteresting/ } \\
\text { routine labor }\end{array}$ & Higher economic efficiency & Increase of unemployment \\
\hline & $\begin{array}{l}\text { Digital biotechnology } \\
\text { management (B.7.1) }\end{array}$ & $\begin{array}{l}\text { The genetic system, } \\
\text { cell, organ }\end{array}$ & Genetic engineering & $\begin{array}{l}\text { Avoiding hereditary disease, } \\
\text { 'improving man' }\end{array}$ & Loss of resilience ... \\
\hline
\end{tabular}




\section{Appendix C. Short Labels, Technology Innovation, and Primary Impact Domains of Unseens}

Table A2. Intended changes and properties if unseens related to the propositons presented in Appendix A.

\begin{tabular}{|c|c|c|c|c|c|}
\hline $\begin{array}{l}\text { Scientist and } \\
\text { Perspective }\end{array}$ & $\begin{array}{l}\text { Label of unseens (Numbers } \\
\text { See Appendix A) }\end{array}$ & $\begin{array}{l}\text { Primary System of } \\
\text { Unseens }\end{array}$ & Technology Innovation & Intended Change & Properties of Unseens \\
\hline \multicolumn{6}{|c|}{ Biotechnological level (Scholz, Japanese ERT) } \\
\hline Scholz (see Appendix A) & $\begin{array}{l}\text { Monsanto's Roundup Ready } \\
\text { and the farmers supply chain }\end{array}$ & Agricultural value chain & $\begin{array}{l}\text { DNA engineering for more yield } \\
\text { and more resilient yield }\end{array}$ & Increase farmer's yield & $\begin{array}{l}\text { Shortening of farmers' participation in the } \\
\text { supply chain (reduction of genetic diversity) }\end{array}$ \\
\hline \multicolumn{6}{|c|}{ European ERT } \\
\hline \multirow{4}{*}{$\begin{array}{l}\text { 1. Schuh and Prote: } \\
\text { Industrial Change }\end{array}$} & $\begin{array}{l}\text { A.1.1 Industrie } 4.0 \text { (security } \\
\text { and competition challenges) }\end{array}$ & Industrial production & $\begin{array}{l}\text { Smart ICT by IoT/industrial } \\
\text { internet }\end{array}$ & $\begin{array}{l}\text { Lean production efficiency (renewal by } \\
\text { human-machine interface }\end{array}$ & $\begin{array}{l}\text { Misallocation of profits to 'data governors' in } \\
\text { cross-domain business; new security across } \\
\text { industry questions arise }\end{array}$ \\
\hline & $\begin{array}{l}\text { A.1.2 Redefining labor } \\
\text { (qualification) }\end{array}$ & $\begin{array}{l}\text { Economics and } \\
\text { professional education }\end{array}$ & $\begin{array}{l}\text { Algorithmic data processing from } \\
\text { many domains possible }\end{array}$ & $\begin{array}{l}\text { Fast, effective (all) and efficient access to } \\
\text { information (processed data) }\end{array}$ & $\begin{array}{l}\text { New interdisciplinary qualifications for white } \\
\text { collar workers; new possibilities for blue collar } \\
\text { workers }\end{array}$ \\
\hline & $\begin{array}{l}\text { A.1.3 Customer driven } \\
\text { production }\end{array}$ & Market dynamics & $\begin{array}{l}\text { Customer-driven production, } \\
\text { shared platforms or clouds }\end{array}$ & $\begin{array}{l}\text { Agile, participatory product } \\
\text { development }\end{array}$ & $\begin{array}{l}\text { Loss of synchronization; significant change of } \\
\text { company culture/processes }\end{array}$ \\
\hline & A.1.4. Platform economics & Industry and trade & $\begin{array}{l}\text { Cyber-physical systems, } \\
\text { cyber-physical product }\end{array}$ & Strengthening industry & $\begin{array}{l}\text { Platform industry/ economy abandons } \\
\text { traditional industry; new winners and losers } \\
{[144,145] \text {, new business models }}\end{array}$ \\
\hline \multirow{4}{*}{$\begin{array}{l}\text { 2. Bartelsman: } \\
\text { Economic Change }\end{array}$} & A.2.1 Knowledge economy & Data market & $\begin{array}{l}\text { Knowledge supplements capital, } \\
\text { labor and natural resources (as a } \\
\text { commodity) }\end{array}$ & Making profit with intangible assets & $\begin{array}{l}\text { Dispersion of productivity and profitability; } \\
\text { change the nature of the products }\end{array}$ \\
\hline & A.2.2 Digitalized labor & $\begin{array}{l}\text { New supply chains ask } \\
\text { for different types of skills }\end{array}$ & $\begin{array}{l}\text { Automatization of routine manual } \\
\text { and analytic work }\end{array}$ & $\begin{array}{l}\text { Substitution by certain types of (physical } \\
\text { or routine) jobs by AI }\end{array}$ & New types of labor skills and resources \\
\hline & A.2.3 Income inequality & $\begin{array}{l}\text { Intangible Productivity } \\
\text { paradox }\end{array}$ & Skewed data & $\begin{array}{l}\text { Marginal decline of profits from tangible } \\
\text { knowledge (change of scarcity); } \\
\text { intellectual capital becomes (partly) } \\
\text { digitalized knowledge }\end{array}$ & $\begin{array}{l}\text { Intangible capital causes new types of economic } \\
\text { growth [146] }\end{array}$ \\
\hline & $\begin{array}{l}\text { A.2.4 (Ambiguity of } \\
\text { intellectual) Property rights }\end{array}$ & $\begin{array}{l}\text { Ambiguity of who is the } \\
\text { generator of a new } \\
\text { "economically profitable" } \\
\text { idea }\end{array}$ & $\begin{array}{l}\text { IoT makes } \\
\text { intangible/dematerialized issues } \\
\text { valuable }\end{array}$ & $\begin{array}{l}\text { Monopoly distortion in the use of goods } \\
\text { produced with transactional data }\end{array}$ & Recalibrate patent rights; copyright law reform \\
\hline \multirow{3}{*}{$\begin{array}{l}\text { 3. Höjer and Hilty: } \\
\text { Environmental Systems }\end{array}$} & $\begin{array}{l}\text { A.3.1 (\& A.3.2) Efficiency } \\
\text { rebounds on environment }\end{array}$ & $\begin{array}{l}\text { Increase of production } \\
\text { and services }\end{array}$ & Increase of efficiency in production & More and cheaper products & $\begin{array}{l}\text { More (cheaper) products and thus more } \\
\text { energy/materials are produced [147] if no } \\
\text { dematerialization of production takes place }\end{array}$ \\
\hline & $\begin{array}{l}\text { A.3.3. Restructured region } \\
\text { (rural home office) }\end{array}$ & Spatial planning & $\begin{array}{l}\text { The meaning of a "workplace" is } \\
\text { changing }\end{array}$ & $\begin{array}{l}\text { Reduced commuting and other daily } \\
\text { travel }\end{array}$ & $\begin{array}{l}\text { Regional consumption and demand changes; } \\
\text { long distance, powerful. stable network }\end{array}$ \\
\hline & A.3.4 Use of buildings & $\begin{array}{l}\text { Economics: Housing and } \\
\text { Construction }\end{array}$ & $\begin{array}{l}\text { Digital services reducing demand } \\
\text { for space. Matching of supply and } \\
\text { demand of interior space. }\end{array}$ & Less buildings needed & $\begin{array}{l}\text { ICT allows for efficient use of energy and } \\
\text { private and commercial space [59] }\end{array}$ \\
\hline
\end{tabular}


Table A2. Cont.

\begin{tabular}{|c|c|c|c|c|c|}
\hline $\begin{array}{l}\text { Scientist and } \\
\text { Perspective }\end{array}$ & $\begin{array}{l}\text { Label of unseens (Numbers } \\
\text { See Appendix A) }\end{array}$ & $\begin{array}{c}\text { Primary System of } \\
\text { Unseens }\end{array}$ & Technology Innovation & Intended Change & Properties of Unseens \\
\hline \multirow{4}{*}{ 4. Montag and Diefenbach } & A.4.1 Human robot & Individual & AI-based robots/decision aids & Better (more rational) decisions & $\begin{array}{l}\text { Decisions of AI-robots has more impact than } \\
\text { human decisions; liability issue unexplained }\end{array}$ \\
\hline & $\begin{array}{l}\text { A.4.3 Fragmented life (and } \\
\text { digital psycho- } \\
\text { neuro-dynamics) }\end{array}$ & Individual, family & $\begin{array}{l}\text { Networked ICT for getting } \\
\text { information and social contacts }\end{array}$ & $\begin{array}{l}\text { More and better online information (at } \\
\text { any time) including gamification [148] }\end{array}$ & $\begin{array}{l}\text { Fragmented life, information overuse by limited } \\
\text { human multiprocessing, digital depression, } \\
\text { internet addiction etc.; neuropsychological, } \\
\text { endocrinological, and epigenetic effect }\end{array}$ \\
\hline & $\begin{array}{l}\text { A.4.4 Psycho-neuro- } \\
\text { endicrinonogical dynamics }\end{array}$ & Individual, cell & Digital media & $\begin{array}{l}\text { Access to more information and } \\
\text { stimulation }\end{array}$ & $\begin{array}{l}\text { Intense exposure to evolutionary new digital } \\
\text { environments causes }\end{array}$ \\
\hline & $\begin{array}{l}\text { A.4.5 (and A.4.4) Digital } \\
\text { depression (emotional needs) }\end{array}$ & Individual well-being & $\begin{array}{l}\text { Networked ICT for getting } \\
\text { information and social interaction } \\
\text { with many people }\end{array}$ & Increasing well-being and happiness & $\begin{array}{l}\text { Critical psychological situations due to limited } \\
\text { emotional feedback by digital vaulting }\end{array}$ \\
\hline \multirow{3}{*}{ 5. Franke: Genetics } & $\begin{array}{l}\text { A.5.1 Genetical } \\
\text { discrimination }\end{array}$ & Human right of privacy & $\begin{array}{l}\text { Reading the genetic code for low } \\
\text { cost }\end{array}$ & $\begin{array}{l}\text { Getting access to information about } \\
\text { diseases }\end{array}$ & $\begin{array}{l}\text { DNA information is easy accessible for low costs } \\
\text { (USD 30) and can be used by health insurance, } \\
\text { job and educational decisions }\end{array}$ \\
\hline & $\begin{array}{l}\text { A.5.2 } \\
\text { Pharmacogenomics [149] }\end{array}$ & Cell, tissue, organ, body & $\begin{array}{l}\text { DNA and disease data allow for } \\
\text { identifying genetically based }\end{array}$ & Reducing costs for developing drugs & $\begin{array}{l}\text { Unknown, e.g., providing floor for new } \\
\text { pathogene ("European Disease" like effects) }\end{array}$ \\
\hline & $\begin{array}{l}\text { A5.3 DNA-based } \\
\text { medical treatment }\end{array}$ & Cells & CRISP-CAS9 technology & $\begin{array}{l}\text { Changing embryo's DNA for avoiding } \\
\text { diseases }\end{array}$ & $\begin{array}{l}\text { What (genetic) diseases at what stage of life } \\
\text { should be cured with what costs; is this a } \\
\text { directed evolution of a critical kind }\end{array}$ \\
\hline \multirow{3}{*}{$\begin{array}{l}\text { 6. Parycek and } \\
\text { Viale Pereira }\end{array}$} & A.6.1 Digital policymaking & $\begin{array}{l}\text { Politics and } \\
\text { administration: } \\
\text { digitalization of public } \\
\text { services and } \\
\text { communication }\end{array}$ & $\begin{array}{l}\text { Data analytics and automated } \\
\text { decision by self-organized digital } \\
\text { environment }\end{array}$ & $\begin{array}{l}\text { More data-based decisions along the } \\
\text { public interests and hybrid forms of } \\
\text { organized cooperation }\end{array}$ & $\begin{array}{l}\text { Rebound effects (i) lack of definition on roles, } \\
\text { actors and data owners (ii) misinterpretation of } \\
\text { demands; (iii) lack of context specific solutions } \\
\text { (technocracy) }\end{array}$ \\
\hline & $\begin{array}{l}\text { A.6.3 (and A.6.2) Resilience } \\
\text { governance; global and } \\
\text { ethics-based }\end{array}$ & Human species & Globally networked IT & $\begin{array}{l}\text { Global, prospective risk/vulnerability } \\
\text { management }\end{array}$ & $\begin{array}{l}\text { Missing anticipation of impacts on "ethical, } \\
\text { environmental, privacy and equality aspects" }\end{array}$ \\
\hline & A.6.4 Cybersocial systems & $\begin{array}{l}\text { Algorithms of data search } \\
\text { and processing on } \\
\text { big data }\end{array}$ & $\begin{array}{l}\text { IoT driven pervasive computing in } \\
\text { all domains of life }\end{array}$ & $\begin{array}{l}\text { Extending, augmenting, and facilitating } \\
\text { human action and cognition }\end{array}$ & $\begin{array}{l}\text { Unknown systemic risks of (erroneous) } \\
\text { operation and maintenance; }\end{array}$ \\
\hline \multirow[t]{2}{*}{$\begin{array}{l}\text { 7. Hill: Cybersecurity } \\
\text { and Warfare }\end{array}$} & $\begin{array}{l}\text { A7.1/A.7.2 Cyberwar } \\
\text { (Digital warfare) }\end{array}$ & $\begin{array}{l}\text { Digital attack as a new } \\
\text { weapon and means of } \\
\text { destruction }\end{array}$ & $\begin{array}{l}\text { Infrastructure (water, electricity, } \\
\text { airline control, health services, ...) is } \\
\text { [and public news/information } \\
\text { systems are] digitally vulnerable }\end{array}$ & $\begin{array}{l}\text { War: =utilization of digital networks } \\
\text { (forces, cyberattacks) for } \\
\text { geopolitical purposes }\end{array}$ & $\begin{array}{l}\text { New, secure IT structures needed, e.g., for IoT; } \\
\text { inadequate and cyberweapons available at } \\
\text { low costs }\end{array}$ \\
\hline & A.7.3 Digital-war convention & $\begin{array}{l}\text { Collective action } \\
\text { against cyberattacks }\end{array}$ & $\begin{array}{l}\text { Ransomware and hacking tools } \\
\text { are available }\end{array}$ & Destruction by cybercriminals and by & A Geneva Digital Convention \\
\hline
\end{tabular}


Table A2. Cont.

\begin{tabular}{|c|c|c|c|c|c|}
\hline $\begin{array}{l}\text { Scientist and } \\
\text { Perspective }\end{array}$ & $\begin{array}{l}\text { Label of unseens (Numbers } \\
\text { See Appendix A) }\end{array}$ & $\begin{array}{c}\text { Primary System of } \\
\text { Unseens }\end{array}$ & Technology Innovation & Intended Change & Properties of Unseens \\
\hline & $\begin{array}{l}\text { A.7.4 Mass surveillance (with } \\
\text { and without the state) }\end{array}$ & $\begin{array}{l}\text { Arbitrary digital storage } \\
\text { and retrieval }\end{array}$ & $\begin{array}{l}\text { Mass surveillance (e.g., for } \\
\text { surveillance economy or political } \\
\text { control) as cyber-attack/war on } \\
\text { the individual }\end{array}$ & $\begin{array}{l}\text { More (economic/political power on } \\
\text { the individual) }\end{array}$ & $\begin{array}{l}\text { Loss of privacy and freedom of thought by } \\
\text { search engines (foundations of democracy); } \\
\text { censorship: hidden undetectable }\end{array}$ \\
\hline & A.7.5 AI warbots & AI driven weapons & $\begin{array}{l}\text { Semi- autonomous or fully } \\
\text { autonomous weapons }\end{array}$ & Losing less soldiers & $\begin{array}{l}\text { Unfriendly fire may emerge; control and } \\
\text { responsibility unclear }\end{array}$ \\
\hline \multirow{3}{*}{$\begin{array}{l}\text { 8. Kirchner and Dowek: } \\
\text { Ethics and the Digital }\end{array}$} & $\begin{array}{l}\text { A.8.1 (- A.8.3) Pervasive } \\
\text { computation ethics }\end{array}$ & $\begin{array}{l}\text { Pervasive computation } \\
\text { machines and computers } \\
\text { invade/merge with }\end{array}$ & $\begin{array}{l}\text { Digitalization provides ubiquitous } \\
\text { availability, 'unlimited' storage, } \\
\text { fast processing, automatization, } \\
\text { AI-driven robotization }\end{array}$ & $\begin{array}{l}\text { Getting deeper ... Ethics as a competitive } \\
\text { argument for industry } 4.0\end{array}$ & $\begin{array}{l}\text { Personal data and public security; cloning and } \\
\text { GMO; diverging cultural ethics on } \\
\text { digital machines }\end{array}$ \\
\hline & $\begin{array}{l}\text { A.8.4 Cybersecurity ethics } \\
\text { (from ethical hacking } \\
\text { to cybersecurity) }\end{array}$ & Data owners & $\begin{array}{l}\text { Hacker tools, sophisticated } \\
\text { technologies of interception, } \\
\text { interruption. modification, and } \\
\text { fabrication [150-152] }\end{array}$ & $\begin{array}{l}\text { Developing New forms/areas of high } \\
\text { security domains }\end{array}$ & $\begin{array}{l}\text { New rules on individual, organizational, public } \\
\text { rights in a space of changing types and } \\
\text { motivations of attacks (e.g., ethical } \\
\text { hacking [153]) }\end{array}$ \\
\hline & A.8.5 Robot ethics & $\begin{array}{l}\text { Semi-autonomous } \\
\text { (learning) adapting robots }\end{array}$ & $\begin{array}{l}\text { New forms and } \\
\text { integration/merging of } \\
\text { human-machine interaction; } \\
\text { autonomous robots }\end{array}$ & $\begin{array}{l}\text { Formal ethics for Intelligent machines } \\
\text { interact/merge with humans }\end{array}$ & $\begin{array}{l}\text { Machines need formal ethics to follow human } \\
\text { ethics; missing "Ethics for, by, and in } \\
\text { design" [154] }\end{array}$ \\
\hline \multirow{3}{*}{$\begin{array}{l}\text { 9. Helbig and Klauser: } \\
\text { Global Social Change }\end{array}$} & A.9.1 Deliberated democracy & $\begin{array}{l}\text { Fostering democratic } \\
\text { participation by digital } \\
\text { communication }\end{array}$ & $\begin{array}{l}\text { A potential for new, uncensored, } \\
\text { fair networked discourses } \\
\text { (MOODs) }\end{array}$ & Empowering democracy & $\begin{array}{l}\text { Filter bubbles and censoring restrict freedom } \\
\text { and unbiased knowledge; no democratic tool as } \\
\text { the web is a private good }\end{array}$ \\
\hline & A.9.2 Finance 4.0 & $\begin{array}{l}\text { Altering the } \\
\text { financial system }\end{array}$ & $\begin{array}{l}\text { The potential to measure, value } \\
\text { and trade positive and negative } \\
\text { externalities }\end{array}$ & Boosting a circular economy & $\begin{array}{l}\text { A multi-dimensional incentive and reward } \\
\text { system beyond money }\end{array}$ \\
\hline & A.9.3 Democratic Capitalism & Innovation & $\begin{array}{l}\text { Monitoring and evaluating global } \\
\text { value creation }\end{array}$ & $\begin{array}{l}\text { Overcoming venture capitalism and } \\
\text { using crowd funding }\end{array}$ & Democracy threatened by capitalism \\
\hline \multirow{3}{*}{$\begin{array}{l}\text { 10. Grunwald and Renn: } \\
\text { Sustainable Development }\end{array}$} & A.10.1 Efficiency rebounds & $\begin{array}{l}\text { Increasing efficiency by } \\
\text { digital monitoring } \\
\text { and governing }\end{array}$ & Technology development & $\begin{array}{l}\text { Sustainable, more efficient technologies } \\
\text { with less energy and materials }\end{array}$ & $\begin{array}{l}\text { More energy and material because of increase of } \\
\text { GDP and less costs }\end{array}$ \\
\hline & $\begin{array}{l}\text { A.10.2 (see A.9.1) } \\
\text { Digital democracy }\end{array}$ & $\begin{array}{l}\text { Fostering democratic } \\
\text { participation by digital } \\
\text { communication }\end{array}$ & $\begin{array}{l}\text { Intelligent software operates on } \\
\text { the web }\end{array}$ & $\begin{array}{l}\text { Improve citizens' information for } \\
\text { democratic action }\end{array}$ & $\begin{array}{l}\text { Political manipulation; selective, personally } \\
\text { biased, opinionated information (reality shift, } \\
\text { Deguchi) loss of privacy, } \\
\text { omnipresent surveillance }\end{array}$ \\
\hline & A.10.3 Redefining labor & $\begin{array}{l}\text { Abandoning boring } \\
\text { routine work }\end{array}$ & $\begin{array}{l}\text { Technology development, digital } \\
\text { services }\end{array}$ & Change of labor demand & Reduction of time in many domains of labor \\
\hline
\end{tabular}




\section{References}

1. Takács-Sánta, A. The major transitions in the history of human transformation of the biosphere. Hum. Ecol. Rev. 2004, 11, 51-66.

2. Wußing, H.-L. 6000 Jahre Mathematik. Eine kulturgeschichtliche Zeitreise. Von den Anfängen bis Leibniz und Newton; Springer: Berlin, Gernamy, 2008.

3. Ifrah, G. The Universal History of Computing: From the Abacus to the Quantum Computer; John Wiley \& Sons, Inc.: New York, NY, USA, 2001.

4. Scholz, R.W. Sustainable digital environments: What major challenges is humankind facing? Sustainability 2016, 8, 726. [CrossRef]

5. Babbage, C. Babbage's Calculating Engines: Being a Collection of Papers Relating to Them, Their History and Construction; Babbage, H.P., Ed.; Cambridge University Press: Cambridge, UK, 2010.

6. Hilbert, M.; López, P. The world's technological capacity to store, communicate, and compute information. Science 2011, 332, 60-65. [CrossRef] [PubMed]

7. Myers, B.A. A Brief History of Human Computer Interaction Technology; Technical Report CMU-CS-96-163; School of Computer Science Technical Pittsburgh, Carnegie Mellon University: Pittsburgh, PA, USA, 1996.

8. Moore, G.E. Cramming more components onto integrated circuits. Electronics 1965, 19, 82-85. [CrossRef]

9. Courtland, R. Gordon Moore: The man whose name means progress. Gordon Moore: The Man Whose Name Means Progress. IEEE Spectrum, 30 March 2015.

10. Zhirnov, V.V.; Cavin, R.K. Future microsystems for information processing: Limits and lessons from the living systems. IEEE J. Electron. Devices Soc. 2013, 1, 29-47. [CrossRef]

11. Trabesinger, A. Quantum computing: Towards reality. Nature 2017, 543, S1. [CrossRef] [PubMed]

12. Mohseni, M.; Read, P.; Neven, H.; Boixo, S.; Denchev, V.; Babbush, R.; Fowler, A.; Smelyanskiy, V.; Martinis, J. Commercialize quantum technologies in five years. Nat. News 2017, 543, 171. [CrossRef] [PubMed]

13. Benenson, Y. Biocomputers: From test tubes to live cells. Mol. Biosyst. 2009, 5, 675-685. [CrossRef] [PubMed]

14. Kassam, Z. Cancer-fighting nano-robots programmed to seek and destroy tumours. In European Pharmaceutical Review; Russell Publishing Ltd.: Brasted, UK, 2018.

15. Forster, S.P.; Stegmaier, J.; Spycher, R.; Seeger, S. Virtual pharmaceutical companies: Collaborating flexibly in pharmaceutical development. Drug Discov. Today 2014, 19, 348-355. [CrossRef] [PubMed]

16. European Commission. Europe's Digital Progress Report 2017, April 27. Available online: https:/ / ec.europa. eu/digital-single-market/en/news/europes-digital-progress-report-2017 (accessed on 11 February 2017).

17. Bundesregierung, G.G.D. Grundsätze Unserer Digitalpolitik. Available online: https://www.digitaleagenda.de/Webs/DA/DE/Grundsaetze/Grundsaetze_Digitalpolitik/grundsaetze-digitalpolitik_node. html (accessed on 11 February 2017).

18. Government of the UK. UK Digital Strategy 2017. Policy Paper. Published 1 March 2017. Department for Digital, Culture, Media \& Sport. Available online: https:/ /www.gov.uk/government/publications/ uk-digital-strategy / uk-digital-strategy\#the-digital-sectors---making-the-uk-the-best-place-to-start-andgrow-a-digital-business (accessed on 11 February 2017).

19. Solow, R.M. We'd better watch out. New York Times Book Review, 12 July 1987; 36.

20. Brynjolfsson, E.; Hitt, L.M. Beyond the productivity paradox. Commun. ACM 1998, 41, 49-55. [CrossRef]

21. Brynjolfsson, E. The productivity paradox of the new digital economy. Commun. ACM 1993, 36, 67-77.

22. Brynjolfsson, E.; McAfee, A. The Second Machine Age: Work, Progress, and Prosperity in a Time of Brilliant Technologies; WW Norton \& Company: New York, NY, USA, 2014.

23. Polak, P. The productivity paradox: A meta-analysis. Inf. Econ. Policy 2017, 38, 38-54. [CrossRef]

24. Van Ark, B. The productivity paradox of the new digital economy. Int. Prod. Monit. 2016, 31, 3-18.

25. Scholz, R.W. Environmental Literacy in Science and Society: From Knowledge to Decisions; Cambridge University Press: Cambridge, UK, 2011.

26. Laws, D.; Scholz, R.W.; Shiroyama, H.; Susskind, L.E.; Suzuki, T.; Weber, O. Expert views on sustainability and technology implementation. Int. J. Sustain. Dev. World Ecol. 2004, 11, 247-261. [CrossRef]

27. Scholz, R.W. The normative dimension in transdisciplinarity, transition management, and transformation sciences: New roles of science and universities in sustainable transitioning. Sustainability 2017, 9, 991. [CrossRef] 
28. Scholz, R.W.; Steiner, G. The real type and the ideal type of transdisciplinary processes. Part I-Theoretical foundations. Sustain. Sci. 2015, 10, 527-544. [CrossRef]

29. Scholz, R.W.; Steiner, G. The real type and the ideal type of transdisciplinary processes. Part II-What constraints and obstacles do we meet in practice? Sustain. Sci. 2015, 10, 653-671. [CrossRef]

30. Transdisciplinarity: Joint Problem Solving among Science, Technology, and Society. An Effective Way for Managing Complexity; Klein, J.T.; Grossenbacher-Mansuy, W.; Häberli, R.; Bill, A.; Scholz, R.W.; Welti, M. (Eds.) Birkhäuser: Basel, Switzerland, 2001.

31. Sugiyama, M.; Deguchi, H.; Ema, A.; Kishimoto, A.; Mori, J.; Shiroyama, H.; Scholz, R.W. Unintended side effects of digital transition: Perspectives of Japanese Experts. Sustainability 2017, 9, 2193. [CrossRef]

32. Sugiyama, M.; Asayama, S.; Kosugi, T.; Ishii, A.; Emori, S.; Adachi, J.; Akimoto, K.; Fujiwara, M.; Hasegawa, T.; Hibi, Y. Transdisciplinary co-design of scientific research agendas: 40 research questions for socially relevant climate engineering research. Sustain. Sci. 2017, 12, 31-44. [CrossRef]

33. Cohen, I.R. Tending Adam's Garden: Evolving the Cognitive Immune Self; Academic Press: London, UK, 2000.

34. Guerder, S.; Matzinger, P. Activation versus tolerance - a decision made by T-helper cells. Cold Spring Harb. Symp. Quant. Biol. 1989, 54, 799-805. [CrossRef] [PubMed]

35. Reichel, A. Technology as system: Towards an autopoietic theory of technology. Int. J. Innov. Sustain. Dev. 2011, 5, 105-118. [CrossRef]

36. Nolan, P.; Lenski, G. Human Societies: An Introduction to Macroscociology, 10th ed.; McGraw-Hill: New York, NY, USA, 2005.

37. Seidl, R.; Brand, F.; Stauffacher, M.; Krütli, P.; Le, Q.B.; Spörri, A.; Meylan, G.; Moser, C.; Berger Gonzales, M.; Scholz, R.W. Science with society in the anthropocene. Ambio 2013, 42, 5-12. [CrossRef] [PubMed]

38. Cohen, I.R. Discrimination and dialogue in the immune system. Semin. Immunol. 2000, 12, $215-219$. [CrossRef] [PubMed]

39. Hansen, K.-H. Science and technology as social relations towards a philosophy of technology for liberal education. In Shaping Concepts of Technology; De Vries, M.J., Arley, T., Eds.; Springer: Berlin, Germany, 1997; pp. 49-63.

40. Scholz, R.W. Digital Threat and Vulnerability Management: The SVIDT Method. Sustainability 2017, 9, 554. [CrossRef]

41. Latour, B. Social theory and the study of computerized work sites. In Information Technology and Changes in Organizational Work: Images and Reflections; Orlikowski, W.A., Walsham, G., Jones, M.R., DeGross, J., Eds.; Chapman-Hill: London, UK, 1996; pp. 295-307.

42. Mueller, P. Constructing climate knowledge with computer models. Wiley Interdiscip. Rev. Clim. Chang. 2010, 1,565-580. [CrossRef]

43. Stevenson, D.E. Science, computational science, and computer science: At a crossroads. Commun. ACM 1994, 37, 85-96. [CrossRef]

44. Dowek, G. Computation, Proof, Machine: Mathematics Enters a New Age; Cambridge University Press: Cambridge, UK, 2015.

45. Loveland, D.W. Automated Theorem Proving. A Logical Basis; North-Holland: Dordrecht, The Netherlands, 1978.

46. Pollack, R. How to believe a machine-checked proof. In Twenty Five Years of Constructive Type Theory; Sambin, G., Smith, J., Eds.; Oxford University Press: Oxford, UK, 1998; pp. 205-221.

47. Yoo, Y.; Henfridsson, O.; Lyytinen, K. Research commentary-The new organizing logic of digital innovation: An agenda for information systems research. Inf. Syst. Res. 2010, 21, 724-735. [CrossRef]

48. Porter, M.E.; Heppelmann, J.E. How Smart, Connected Products Are Transforming Competition. Harv. Bus. Rev. 2014, 92, 64-88.

49. Janssen, M.; Wimmer, M.A. Introduction to policy-making in the digital age. In Policy Practice and Digital Science; Springer: Berlin, Germany, 2015; pp. 1-14.

50. Yang, J.; He, S.; Lin, Y.; Lv, Z. Multimedia cloud transmission and storage system based on internet of things. Multimed. Tools Appl. 2017, 76, 17735-17750. [CrossRef]

51. Xiao, L.; Xu, D.; Xie, C.; Mandayam, N.B.; Poor, H.V. Cloud storage defense against advanced persistent threats: A prospect theoretic study. IEEE J. Sel. Areas Commun. 2017, 35, 534-544. [CrossRef]

52. Prahlad, A.; Kottomtharayil, R.; Kavuri, S.; Gokhale, P.; Vijayan, M. Cloud Storage and Networking Agents, Including Agents for Utilizing Multiple, Different Cloud Storage Sites. U.S. Patents 8849955B2, 30 September 2014. 
53. Stanek, J.; Sorniotti, A.; Androulaki, E.; Kencl, L. A secure data deduplication scheme for cloud storage. In Proceedings of the International Conference on Financial Cryptography and Data Security, Christ Church, Barbados, 3-7 March 2014; pp. 99-118.

54. Satyanarayanan, M. Pervasive computing: Vision and challenges. IEEE Pers. Commun. 2001, 8, 10-17. [CrossRef]

55. Aldenderfer, M.S.; Blashfield, R.K. Cluster Analysis; Sage: Newbury Park, CA, USA, 1984.

56. Janssen, J.; Laatz, W. Statistische Datenanalyse Mit SPSS: Eine Anwendungsorientierte Einführung in das Basissystem und das Modul Exakte Tests; Springer: Berlin, Germany, 2016.

57. Geertz, C. Thick description: Toward an interpretive theory of culture. In The Interpretation of Cultures: Selected Essays; Geertz, C., Ed.; Harper Collins: New York, NY, USA, 1973; pp. 3-30.

58. O'Dwyer, K.J.; Malone, D. Bitcoin mining and its energy footprint. In Proceedings of the 25th IET Irish Signals Systems Conference 2014 and 2014 China-Ireland International Conference on Information and Communications Technologies (ISSC 2014/CIICT 2014), Limerick, Ireland, 26-27 June 2014; pp. 280-285.

59. Montag, C.; Diefenbach, S. Towards Homo Digitalis: Important research issues for psychology and the neurosciences at the aawn of the internet of things and the digital society. Sustainability 2018, 10, 415. [CrossRef]

60. Lu, Z.X. From E-heroin to E-Sports: The development of competitive gaming in China. Int. J. Hist. Sport 2016, 33, 2186-2206. [CrossRef]

61. McGrath, J.E. Groups: Interaction and Performance; Prentice-Hall: Englewood Cliffs, NJ, USA, 1984; p. 287.

62. Thibaut, J.W.; Kelley, H.H. The Social Psychology of Groups; Wiley: New York, NY, USA, 1959.

63. Crott, H.W. Soziale Interaktion und Gruppenprozesse [Social Interaction and Group Processes]; Kohlhammer: Stuttgart, Germany, 1979.

64. McKenna, K.Y.A.; Green, A.S. Virtual group dynamics. Group Dyn.-Theory Res. Pr. 2002, 6, 116-127. [CrossRef]

65. Mann, R.P.; Helbing, D. Optimal incentives for collective intelligence. Proc. Natl. Acad. Sci. USA 2017. [CrossRef] [PubMed]

66. Leung, L. Loneliness, self-disclosure, and ICQ ("I seek you”) use. CyberPsychol. Behav. 2002, 5, $241-251$. [CrossRef] [PubMed]

67. Merton, R.K. Science, technology and society in the seventeenth century England. Osiris 1938, 4, 360-632. [CrossRef]

68. Merton, R.K. Science and Democratic Social Structure. Social Theory and Social Structure; Free Press: Glencoe, UK, 1957; pp. 604-615.

69. Pilkington, M. Blockchain technology: Principles and applications. In Research Handbook on Digital Transformations; Olleros, F.X., Zhegu, M., Eds.; Edward Elgar: Broadheath, UK, 2016; pp. 225-253.

70. Lewis, R.D.; Gates, M. Leading Across Cultures; Nicholas Brealey: London, UK, 2005.

71. Helbing, D. Thinking Ahead-Essays on Big Data, Digital Revolution, and Participatory Market Society; Springer: Cham, Switzerland, 2015.

72. Helbing, D.; Pournaras, E. Society: Build digital democracy. Nature 2015, 527, 33-34. [CrossRef] [PubMed]

73. EU. The EU General Data Protection Regulation (GDPR), Agreed Text; Council of the European Union: Brussels, Belgium, 2018.

74. Hasson, F.; Keeney, S.; McKenna, H. Research guidelines for the Delphi survey technique. J. Adv. Nurs. 2000, 32, 1008-1015. [PubMed]

75. Landeta, J. Current validity of the Delphi method in social sciences. Technol. Forecast. Soc. Chang. 2006, 73, 467-482. [CrossRef]

76. Jeschke, S.; Brecher, C.; Meisen, T.; Özdemir, D.; Eschert, T. Industrial Internet of Things and Cyber Manufacturing Systems. In Industrial Internet of Things; Jeschke, S., Brecher, C., Song, H., Rawat, D.B., Eds.; Springer International Publishing: Cham, Switzerland, 2017; pp. 3-19.

77. Monostori, L.; Kádár, B.; Bauernhansl, T.; Kondoh, S.; Kumara, S.; Reinhart, G.; Sauer, O.; Schuh, G.; Sihn, W.; Ueda, K. Cyber-physical systems in manufacturing. CIRP Ann.-Manuf. Technol. 2016, 65, 621-641. [CrossRef]

78. Engineering Valley_Internet of Production auf dem RWTH Aachen Campus: Festschrift für Univ.-Prof. em. Dr.-Ing. Dipl.-Wirt. Ing. Dr. h. c. mult. Walter Eversheim. 1; Schuh, G.; Brecher, C.; Klocke, F.; Schmitt, R. (Eds.) Apprimus Verlag: Aachen, Germany, 2017; p. 460.

79. Stricker, N.; Pfeiffer, A.; Moser, E.; Kádár, B.; Lanza, G.; Monostori, L. Supporting multi-level and robust production planning and execution. CIRP Ann. 2015, 64, 415-418. [CrossRef] 
80. Internet of Production für agile Unternehmen: AWK Aachener Werkzeugmaschinen-Kolloqu. 2017, 18. bis 19. Mai. 1; Schuh, G.; Brecher, C.; Klocke, F.; Schmitt, R. (Eds.) Apprimus Verlag: Aachen, Germany, 2017; p. 460.

81. Cooper, R.G.; Sommer, A.F. The Agile-Stage-Gate Hybrid Model: A Promising New Approach and a New Research Opportunity: The Agile-Stage-Gate Hybrid Model. J. Prod. Innov. Manag. 2016, 33, 513-526. [CrossRef]

82. Mokyr, J.; Vickers, C.; Ziebarth, N.L. The History of Technological Anxiety and the Future of Economic Growth: Is This Time Different? J. Econ. Perspect. 2015, 29, 31-50. [CrossRef]

83. Acemoglu, D.; Autor, D. Skills, Tasks and Technologies: Implications for Employment and Earnings. In Handbook of Labor Economics; Elsevier: New York, NY, USA, 2011; Volume 4, pp. 1043-1171.

84. Boldrin, M.; Levine, D.K. The Case Against Patents. J. Econ. Perspect. 2013, 27, 3-22. [CrossRef]

85. Hilty, L.M. Computing Efficiency, Sufficiency, and Self-Sufficiency: A Model for Sustainability? Available online: https:/ / doi.org/10.5167/uzh-110766 (accessed on 11 April 2018).

86. Hilty, L.M. El papel de las TIC en la Productividad Laboral y de los Recursos. Estamos Utilizando la Innovacion Technologica de Forma Equivocada? Novatica 2015, 234, 32-35.

87. Börjesson Rivera, M.; Håkansson, C.; Svenfelt, Å.; Finnveden, G. Including second order effects in environmental assessments of ICT. Environ. Model. Softw. 2014, 56, 105-115. [CrossRef]

88. Höjer, M.; Moberg, Å.; Henriksson, G. Digitalisering och Hållbar Konsumtion; Sverige Naturvårdsverket: Stockholm, Sweden, 2015.

89. Kramers, A.; Höjer, M.; Lövehagen, N.; Wangel, J. Smart sustainable cities-Exploring ICT solutions for reduced energy use in cities. Environ. Model. Softw. 2014, 56, 52-62. [CrossRef]

90. Lundén, D.; Karagianni, C. Telia-Case: Internal Report; Telia: Stockholm, Sweden, 2018.

91. Höjer, M.; Ringenson, T.; Erman, M. Digitalisation for environmental sustainability in a regional context-A four-step principle. In Proceedings of the 2nd International Conference Smart and Sustainable Planning for Cities and Regions 2017, Bolzano, Italy, 22-24 March 2017; pp. 150-151.

92. Höjer, M.; Mjörnell, K. Measures and Steps for more Efficient Use of Buildings. Sustainability 2018, 10, 1949. [CrossRef]

93. Ullrich, D.; Butz, A. Social Robots for the 21st Century. Computer 2016, 49, 88-92. [CrossRef]

94. Ullrich, D.; Diefenbach, S. Truly Social Robots-Understanding Human-Robot Interaction from the Perspective of Social Psychology. In Proceedings of the 2017 HUCAPP International Conference on Human Computer Interaction Theory and Applications, Porto, Portugal, 27 February-1 March 2017; pp. 39-45.

95. Diefenbach, S.; Christoforakos, L. The Selfie Paradox: Nobody Seems to Like Them Yet Everyone Has Reasons to Take Them. An Exploration of Psychological Functions of Selfies in Self-Presentation. Front. Psychol. 2017, 8, 7. [CrossRef] [PubMed]

96. Montag, C.; Reuter, M. Molecular Genetics, Personality, and Internet Addiction Revisited. In Internet Addiction; Montag, C., Reuter, M., Eds.; Springer International Publishing: Cham, Switzerland, 2017; pp. 141-160.

97. Montag, C.; Duke, É.; Reuter, M. A short summary of neuroscientific findings on Internet addiction. In Internet Addiction; Montag, C., Reuter, M., Eds.; Springer: Berlin, Germany, 2017; pp. 209-218.

98. Gindrat, A.-D.; Chytiris, M.; Balerna, M.; Rouiller, E.M.; Ghosh, A. Use-dependent cortical processing from fingertips in touchscreen phone users. Curr. Biol. 2015, 25, 109-116. [CrossRef] [PubMed]

99. Montag, C.; Duke, É.; Markowetz, A. Toward Psychoinformatics: Computer Science Meets Psychology. Comput. Math. Methods Med. 2016, 2016, 1-10. [CrossRef] [PubMed]

100. Panksepp, J. Cross-species affective neuroscience decoding of the primal affective experiences of humans and related animals. PLoS ONE 2011, 6, e21236. [CrossRef] [PubMed]

101. Diefenbach, S.; Ulrich, D. Wie neue Medien Unser Glücksempfinden Verändern; Digitale Depression; MGV: München, Germany, 2016.

102. Przybylski, A.K.; Weinstein, N. Can you connect with me now? How the presence of mobile communication technology influences face-to-face conversation quality. J. Soc. Pers. Relatsh. 2013, 30, 237-246. [CrossRef]

103. Viale Pereira, G.; Cunha, M.A.; Lampoltshammer, T.J.; Parycek, P.; Testa, M.G. Increasing collaboration and participation in smart city governance: A cross-case analysis of smart city initiatives. Inf. Technol. Dev. 2017, 23, 526-553. [CrossRef]

104. Willke, H. Smart Governance: Governing the Global Knowledge Society; Campus-Verl: Frankfurt, Germany, 2007 ; p. 222.

105. Carsten Stahl, B. IT for a better future: How to integrate ethics, politics and innovation. J. Inf. Commun. Ethics Soc. 2011, 9, 140-156. [CrossRef] 
106. Markus, M.L.; Mentzer, K. Foresight for a responsible future with ICT. Inf. Syst. Front. 2014, 16, 353-368. [CrossRef]

107. Hill, R. Dealing with cyber security threats: International cooperation, ITU, and WCIT. In Proceedings of the 2015 7th International Conference on Cyber Conflict: Architectures in Cyberspace, Tallinn, Estonia, 26-29 May 2015; pp. 119-134.

108. Freeman, K.D. Financial Warfare Threatens America. Global Economic Warfare. Available online: https: / /globaleconomicwarfare.com/2015/03/financial-warfare-threatens-america-2/ (accessed on 11 June 2018).

109. Powers, S.M.; Jablonski, M. The Real Cyber War: The Political Economy of Internet Freedom; University of Illinois Press: Urbana, IL, USA, 2015; p. 269.

110. Kende, M. Global Internet Report 2016; Internet Society: Reston, VA, USA, 2016.

111. Bildt, C.; Smith, G. The one and future internet. J. Cyber Policy 2016, 1, 142-156. [CrossRef]

112. Schmitt, C. The Quest for Privacy. ITU Workshop on Future Trust and Knowledge Infrastructure, Phase 2. Available online: http://www.csg.uzh.ch/csg/en/news/Presentation-at-ITU-T-Workshop-Trust.html (accessed on 11 February 2018).

113. Hern, A.; Gibbs, S. What Is WannaCry Ransomware and Why Is It Attacking Global Computers? The Guardian. 2017. Available online: https:/ /www.theguardian.com/technology/2017/may/12/nhsransomware-cyber-attack-what-is-wanacrypt0r-20 (accessed on 12 May 2017).

114. Vault 7. CIA Hacking Tools Revealed. Available online: https://wikileaks.org/ciav7p1/\# (accessed on 30 April 2018).

115. Smith, B. The Need for Urgent Collective Action to Keep People Safe Online: Lessons from Last Week's Cyberattack. In Microsoft on the Issues. Available online: https://blogs.microsoft.com/on-the-issues/2017/ 05/14/need-urgent-collective-action-keep-people-safe-online-lessons-last-weeks-cyberattack/ (accessed on 15 May 2018).

116. Antsaklis, P. Editorial Control Systems and the Quest for Autonomy. IEEE Trans. Autom. Control 2017, 62, 1013-1016. [CrossRef]

117. Marchant, G.E.; Allenby, B.; Arkin, R.C.; Barrett, E.T.; Borenstein, J.; Gaudet, L.M.; Kittrie, O.; Lin, P.; Lucas, G.R.; O’Meara, R. International Governance of Autonomous Military Robots. Sci. Tech. Law Rev. 2011, 12, 272-315.

118. Dowek, G.; Guiraud, D.; Kirchner, C.; Le Métayer, D.; Oudeyer, P.-Y. Rapport sur la Création d'un Comité D'éthique en Sciences et Technologies du Numérique; Rapp. Technique; INRIA: Le Cesnay, France, 2009.

119. Jaishankar, D. Brexit: The First Major Casualty Of Digital Democracy. 27 June 2016. HuffPost India 2016. Available online: http:/ / www.huffingtonpost.in/dhruva-jaishankar/brexit-the-first-major-ca_b_10695964. html (accessed on 11 February 2017).

120. Helbing, D.; Klauser, S. How to Make Democracy Work in the Digital Age; ETH Zurich: Zürich, Switzerland, 2016. Available online: https://www.researchgate.net/publication/305571691_How_to_make_democracy_ work_\T1 \textquotedblleftin_the_digital_age (accessed on 11 February 2017).

121. Helbing, D. Digitization 2.0: A New Game Begins. June 2017. Available online: https:/ /www.researchgate. net/publication/317279118_Digitization_20_A_New_Game_Begins (accessed on 11 February 2017).

122. Ostrom, E. A polycentric approach for coping with climate change. Ann. Econ. Finance 2014, 15, 71-108.

123. Helbing, D. City and Climate Olympics. Available online: https://www.youtube.com/watch?v=di_Qf1nR_ XA (accessed on 11 July 2018).

124. Beier, G.; Niehoff, S.; Ziems, T.; Xue, B. Sustainability aspects of a digitalized industry-A comparative study from China and Germany. Int. J. Precis. Eng. Manuf.-Green Technol. 2017, 4, 227-234. [CrossRef]

125. Kostakis, V.; Roos, A.; Bauwens, M. Towards a political ecology of the digital economy: Socio-environmental implications of two competing value models. Environ. Innov. Soc. Transit. 2016, 18, 82-100. [CrossRef]

126. Friedewald, M.; Pohoryles, R.J. Privacy and Security in the Digital Age: Privacy in the Age of Super-Technologies; Routledge: London, UK, 2016.

127. Howard, P.N. Pax Technica: How the Internet of Things May Set Us Free or Lock Us Up; Yale University Press: New Haven, CT, USA, 2015; p. 320.

128. Garrity, J. Getting Connected: The Internet and its role as a global public good. Georget. J. Int. Aff. 2017, 18, 6-8. [CrossRef]

129. Rains, S.A.; Tsetsi, E. Social support and digital inequality: Does Internet use magnify or mitigate traditional inequities in support availability? Commun. Monogr. 2017, 84, 54-74. [CrossRef] 
130. Hartl, D.L.; Clark, A.G. Principles of Population Genetics; Sinauer associates: Sunderland, MA, USA, 1997; Volume 116.

131. Dawkins, R. The Selfish Gene; Oxford University Press: Oxford, UK, 2016.

132. Maynard Smith, J. The concept of information in biology. Philos. Sci. 2000, 67, 177-194. [CrossRef]

133. Wilson, D.S.; Sober, E. Reviving the superorganism. J. Theor. Biol. 1989, 136, 337-356. [CrossRef]

134. Wilson, D.S.; Sober, E. Multilevel selection and the return of group-level functionalism-Response. Behav. Brain Sci. 1998, 21, 305-306. [CrossRef]

135. Hölldobler, B.; Wilson, E.O. The Superorganism: The Beauty, Elegance, and Strangeness of Insect Societies; WW Norton \& Company: New York, NY, USA, 2009.

136. Jablonka, E.; Lamb, M.J. Precis of Evolution in Four Dimensions. Behav. Brain Sci. 2007, 30, 353-365. [CrossRef] [PubMed]

137. Esau, M.; Rozema, M.; Zhang, T.H.; Zeng, D.; Chiu, S.; Kwan, R.; Moorhouse, C.; Murray, C.; Tseng, N.-T.; Ridgway, D.; et al. Solving a four-destination traveling salesman problem using escherichia coli cells as biocomputers. ACS Synth. Biol. 2014, 3, 972-975. [CrossRef] [PubMed]

138. Geraci, R.M. Spiritual robots: Religion and our scientific view of the natural world. Theol. Sci. 2006, 4, 229-246. [CrossRef]

139. Wong, P.-H. The public and geoengineering decision-making: A view from Confucian political philosophy. Techné Res. Philos. Technol. 2013, 17, 350-367. [CrossRef]

140. Lee, H.R.; Sabanović, S. Culturally variable preferences for robot design and use in South Korea, Turkey, and the United States. In Proceedings of the 2014 ACM/IEEE international conference on Human-robot interaction. HRI '14, Bielefeld, Germany, 3-6 March 2014; pp. 17-24.

141. Frey, C.B.; Osborne, M. The Future of Employment. How Susceptible are Jobs to Computerisation; University of Oxford: Oxford, UK, 2013.

142. Love, T.; Laier, C.; Brand, M.; Hatch, L.; Hajela, R. Neuroscience of internet pornography addiction: A review and update. Behav. Sci. 2015, 5, 388-433. [CrossRef] [PubMed]

143. Ley, D.; Prause, N.; Finn, P. The emperor has no clothes: A review of the 'pornography addiction' model. Curr. Sex. Health Rep. 2014, 6, 94-105. [CrossRef]

144. Kenney, M.; Zysman, J. The rise of the platform economy. Issues Sci. Technol. 2016, 32, 61.

145. Kenney, M.; Zysman, J. Choosing a future in the platform economy: The implications and consequences of digital platforms (draft paper). In Proceedings of the Kauffman Foundation New Entrepreneurial Growth Conference, Amelia Island, FL, USA, 18-19 June 2015.

146. Corrado, C.; Hulten, C.; Sichel, D. Intangible capital and US economic growth. Rev. Income Wealth 2009, 55, 661-685. [CrossRef]

147. Girod, B.; de Haan, P.; Scholz, R.W. Consumption-as-usual instead of ceteris paribus assumption for demand-Integration of potential rebound effects into LCA. Int. J. Life Cycle Assess. 2011, 16, 3-11. [CrossRef]

148. Seaborn, K.; Fels, D.I. Gamification in theory and action: A survey. Int. J. Hum.-Comput. Stud. 2015, 74, $14-31$. [CrossRef]

149. Roden, D.M.; Wilke, R.A.; Kroemer, H.K.; Stein, C.M. Pharmacogenomics: The genetics of variable drug responses. Circulation 2011, 123, 1661-1670. [CrossRef] [PubMed]

150. Pfleeger, C.P.; Pfleeger, S.L. Security in Computing, 4th ed.; Prentice Hall: Upper Saddle River, NJ, USA, 2007.

151. Stallings, W. Cryptography and Network Security: Principles and Practices; Pearson Education India: London, UK, 2006.

152. Christen, M.; Gordijn, B.; Weber, K.; van de Poel, I.; Yaghmaei, E. A review of value-conflicts in cybersecurity. ORBIT J. 2017, 1. [CrossRef]

153. Regalado, D.; Harris, S.E.; Harper, A.; Eagle, C.; Ness, J.; Spasojevic, B.; Linn, R.; Sims, S. Gray Hat Hacking The Ethical Hacker's Handbook; McGraw-Hill Education Group: New York, NY, USA, 2015.

154. Dignum, V. Ethics in Artificial Intelligence: Introduction to the Special Issue; Springer: Berlin, Germany, 2018.

(C) 2018 by the authors. Licensee MDPI, Basel, Switzerland. This article is an open access article distributed under the terms and conditions of the Creative Commons Attribution (CC BY) license (http://creativecommons.org/licenses/by/4.0/). 